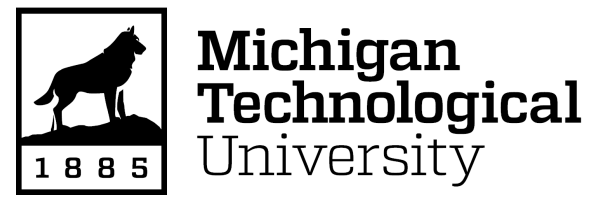

Michigan Technological University Digital Commons @ Michigan Tech

Dissertations, Master's Theses and Master's Reports

2017

\title{
Human Centered Design of an Open-Drum, Treadle Thresher for Quinoa Farmers in the Andes of Northern Peru
}

Robert A. Hayes

Michigan Technological University, rahayes@mtu.edu

Copyright 2017 Robert A. Hayes

\section{Recommended Citation}

Hayes, Robert A., "Human Centered Design of an Open-Drum, Treadle Thresher for Quinoa Farmers in the Andes of Northern Peru", Open Access Master's Report, Michigan Technological University, 2017.

https://doi.org/10.37099/mtu.dc.etdr/435

Follow this and additional works at: https://digitalcommons.mtu.edu/etdr

Part of the Other Mechanical Engineering Commons 
HUMAN CENTERED DESIGN OF AN OPEN-DRUM, TREADLE THRESHER FOR QUINOA FARMERS IN THE ANDES OF NORTHERN PERU

By

Robert A. Hayes

\author{
A REPORT \\ Submitted in partial fulfillment of the requirements for the degree of \\ MASTER OF SCIENCE \\ In Mechanical Engineering \\ MICHIGAN TECHNOLOGICAL UNIVERSITY \\ 2017 \\ (C) 2017 Robert A. Hayes
}


This report has been approved in partial fulfillment of the requirements for the Degree of MASTER OF SCIENCE in Mechanical Engineering.

Department of Mechanical Engineering- Engineering Mechanics

Report Advisor: Dr. John K. Gershenson

Committee Member: Dr. Michele H. Miller

Committee Member: $\quad$ Dr. Kari B. Henquinet

Department Chair: Dr. William W. Predebon 


\section{Table of Contents}

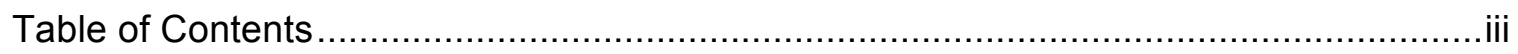

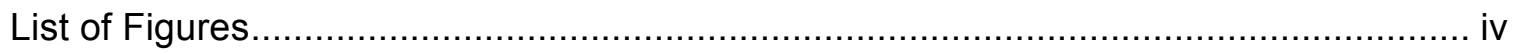

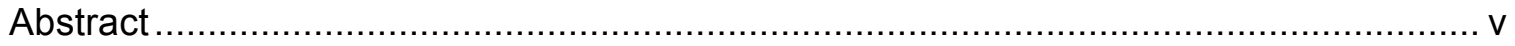

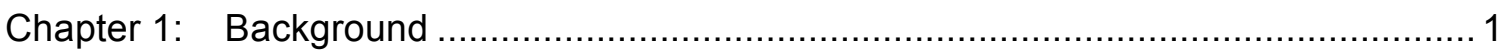

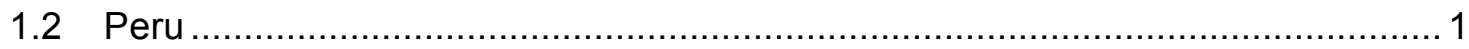

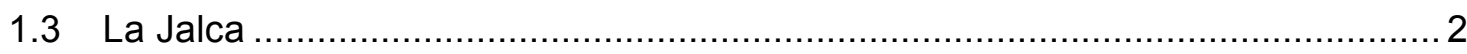

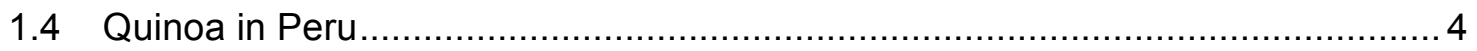

1.4.1 Traditional Harvest and Post-Harvest Preparation of Quinoa ........................ 5

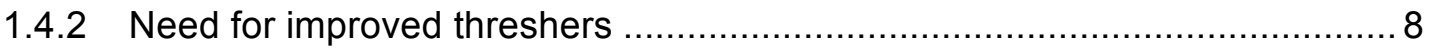

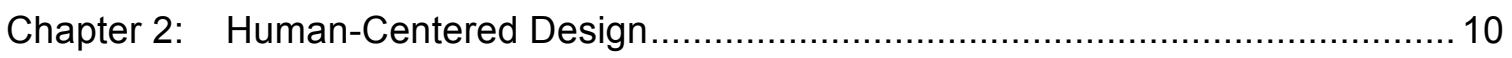

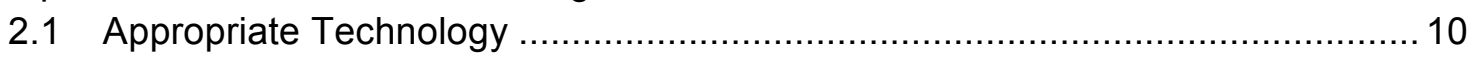

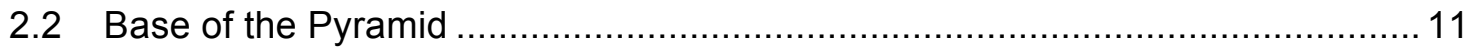

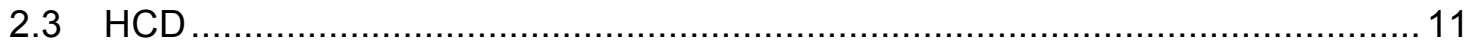

2.4 Criteria for Desirability in Product Design ................................................ 12

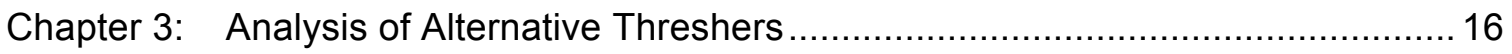

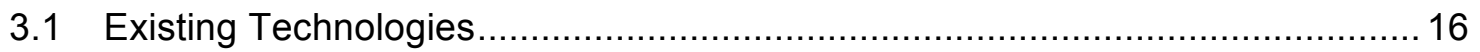

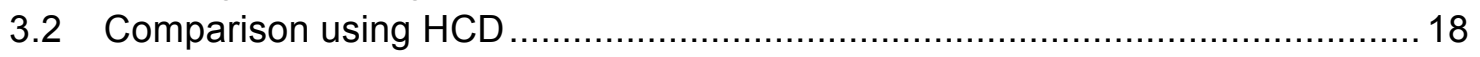

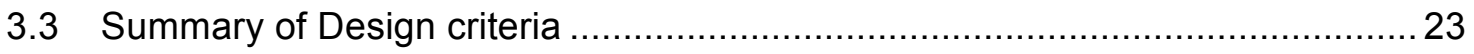

Chapter 4: Design, Construction and Demonstration of a Prototype ......................... 24

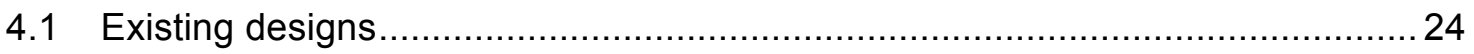

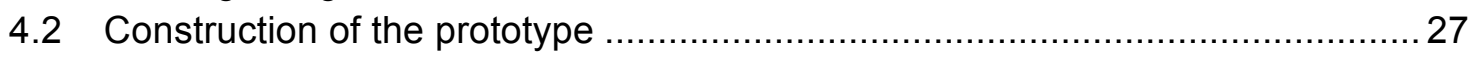

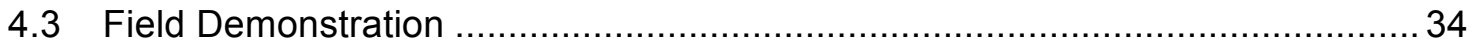

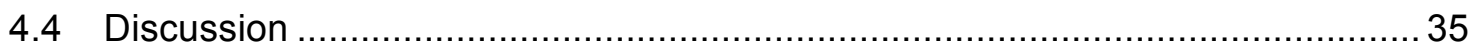

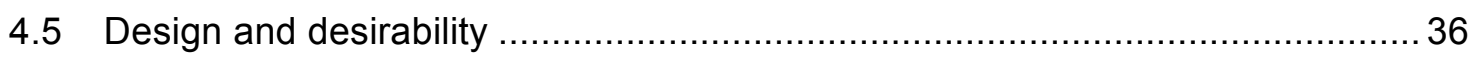

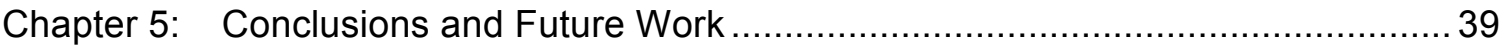

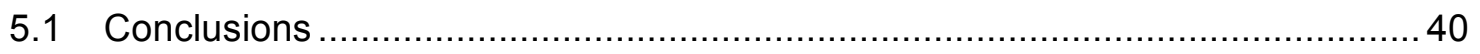

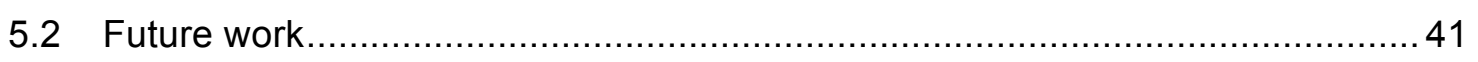

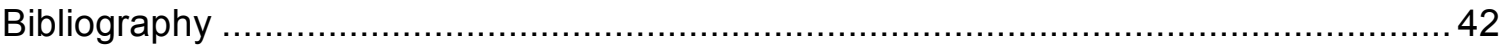




\section{List of Figures}

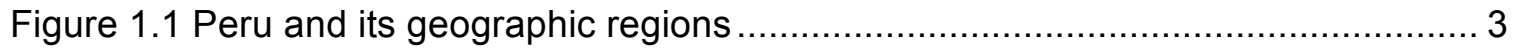

Figure 1.2 Satellite imagery of La Jalca and surrounding farmland ............................. 3

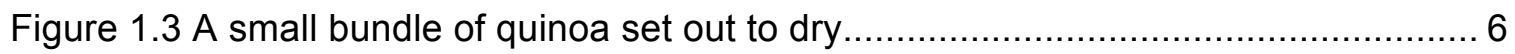

Figure 1.4 Traditional threshing of quinoa .............................................................. 7

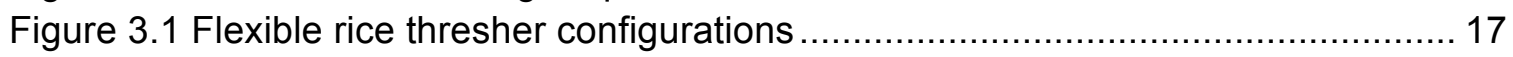

Figure 3.2: Map showing accessibility of La Jalca ............................................... 20

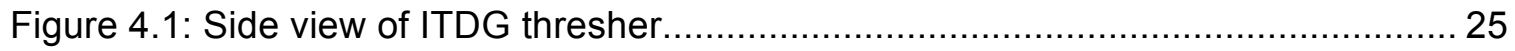

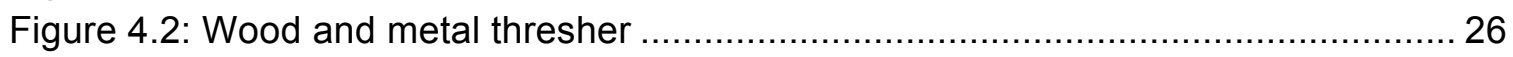

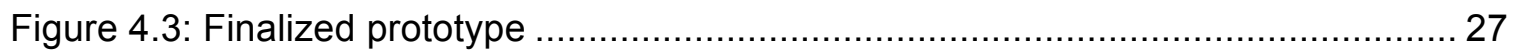

Figure 4.4: Fully assembled drum demonstrating offset teeth................................... 28

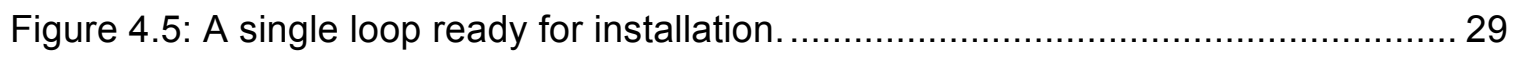

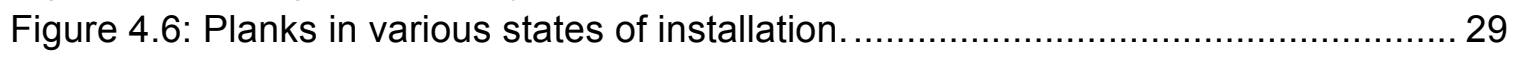

Figure 4.7: Underside of a completed plank. ................................................. 30

Figure 4.8: Dashed line showing portion of the bicycle frame that was removed........... 31

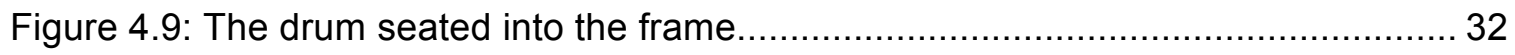

Figure 4.10: Thresher with crank arm shortened ............................................. 33

Figure 4.11: Demonstrating the functionality of the completed prototype ...................... 35 


\section{Abstract}

Growing international demand for quinoa in recent years has led to increased production throughout its South American range, including the Peruvian Andes. Small-scale farmers, who are among the poorest Peruvians, are increasingly growing quinoa for both food security and economic benefit; however, manual harvesting activities, such as threshing, are labor-intensive and time-consuming. This report documents the design, construction and operation of prototype quinoa thresher in a rural village in Northern Peru. In addition, an overview of the history and evolutionary approach to design for the developing world is presented. From this overview, a series of criteria is considered for the design of desirable products for the developing world, including iterative improvement of prototypes. Finally, through the lens these criteria, improvements upon the prototype quinoa thresher are proposed to enhance the likelihood of adoption by Peruvian farmers. 



\section{Chapter 1: Background}

The following report was inspired by my experience as a Peace Corps Master's International student living for two years in Peru. Over the course of my service, I saw in my village of La Jalca a dependence on manual labor to accomplish many tasks such as the hand-spinning of wool and weeding fields of potatoes. In my second year of service, a farmers' cooperative was founded in La Jalca with the intention of growing quinoa as a cash crop. Quinoa is notoriously labor-intensive to cultivate, but I knew from my work at Michigan Tech that human-powered machinery could be a possible approach for easing the burden of labor on smallholder farmers. After delving deeper into the topic of treadle grain threshers, I encountered several existing plans, and I approached local craftsmen to assist in the adaptation of existing designs, in addition to the construction. The result of this collaboration was a functioning prototype of a treadle-powered thresher, which was used by the cooperative during the harvest season prior to my leaving La Jalca for the last time as a Volunteer. The purpose of this report is to describe the HumanCentered Design approach that I pursued as applied to agricultural implements in the developing world, to analyze threshing alternatives through the lens of HCD, and to discuss the next steps in the implementation of the technology going forward.

\subsection{Peru}

Peru is located in the western South America, with neighbors of Chile and Bolivia to the south, Brazil to the east, and Colombia and Ecuador to the north. Its western border is the Pacific Ocean. Peru is divided into 25 administrative entities called departments. Additionally, the country is divided into three geographic regions: the desert coast along the Pacific (Costa), the Andes mountains which run north-to-south through the country (Sierra), and the Amazon rainforest in the east (Selva). Generally speaking, these three regions share similar sociocultural characteristics, and it is often useful to speak in terms of these regions, rather than specific departments. 


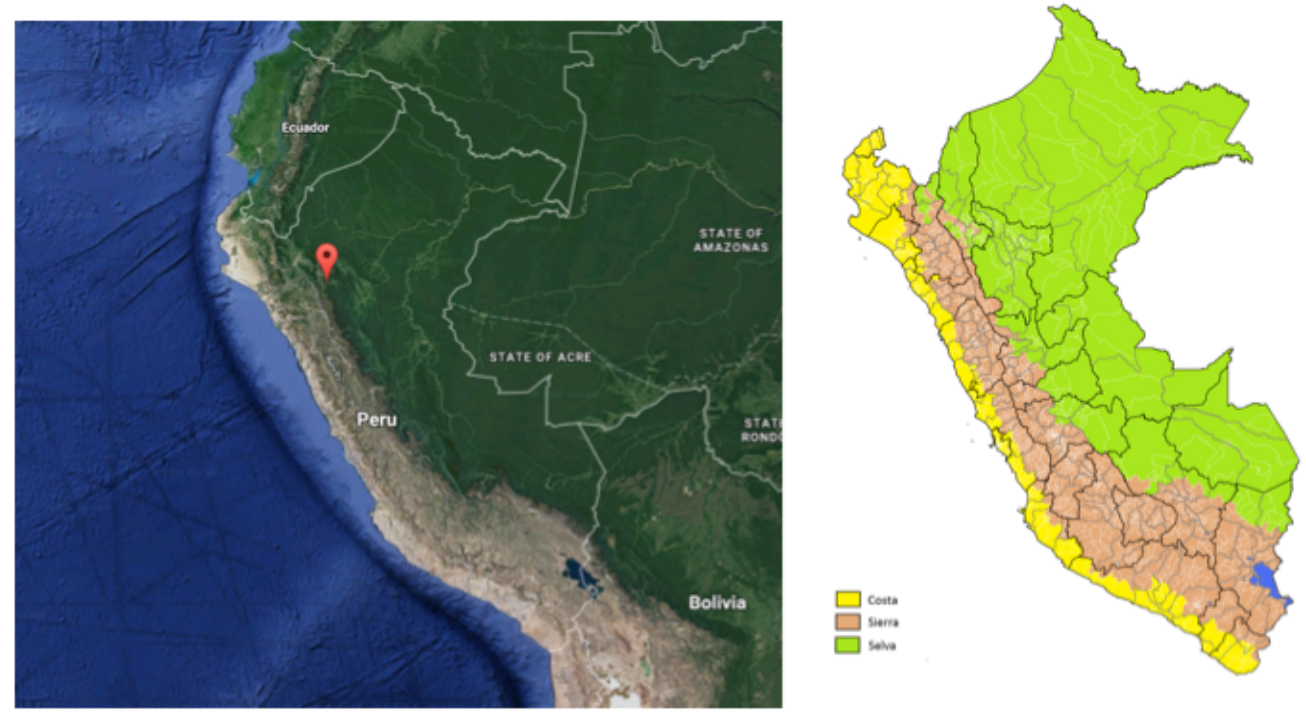

Figure 1.1 Left, satellite image of Peru and surrounding countries. The red pin indicates the town of La Jalca Grande, where I was Peace Corps Volunteer. Source: Google Maps

2016. Right, political map of the departments of Peru, with overlay of geographic regions. Author: ErickAgain, Wikipedia Commons, Creative Commons, CC-BY-SA-3.0

Although Peru has experienced an economic boom in recent years, with mining, commercial fishing, and agricultural as its primary industries, poverty is still the reality for many Peruvians, particularly among those who live in the highlands of the Sierra. According to a 2012 study of poverty by the Peruvian National Institute of Statistics and Information, $68 \%$ of Peruvians in the rural Sierra were found to be living below the poverty line, i.e. able to meet their need for food, but unable to afford other essential needs such as clothing, housing, health, and education. Furthermore, 13\% of all Peruvians of the Sierra were found to be living in extreme poverty, unable to afford their daily caloric needs. Among the poor of both groups, the predominant economic activity is agriculture (INEI, 2016). To increase household income for farmers, one important strategy has been to cultivate crops with a high market value. In the Sierra, the production of quinoa has become a way for the rural poor to augment their household income, and it is associated with better nutrition and economic outcomes compared with non-quinoa growing households (Bellemare, 2016).

\subsection{La Jalca}

The District of La Jalca Grande is located in Chachapoyas Province in the Department of Amazonas. According to the 2007 census, the district of La Jalca Grande had an estimated 5505 inhabitants across over twenty communities of varying sizes. The 
smaller of these communities are no more than 20 households. The largest of these is the capital city, also called La Jalca, which comprises more than half of the population of the district. The district itself is among the poorest in Peru, with more than $80 \%$ of Jalquinos living under the poverty line. (INEI, 2009)

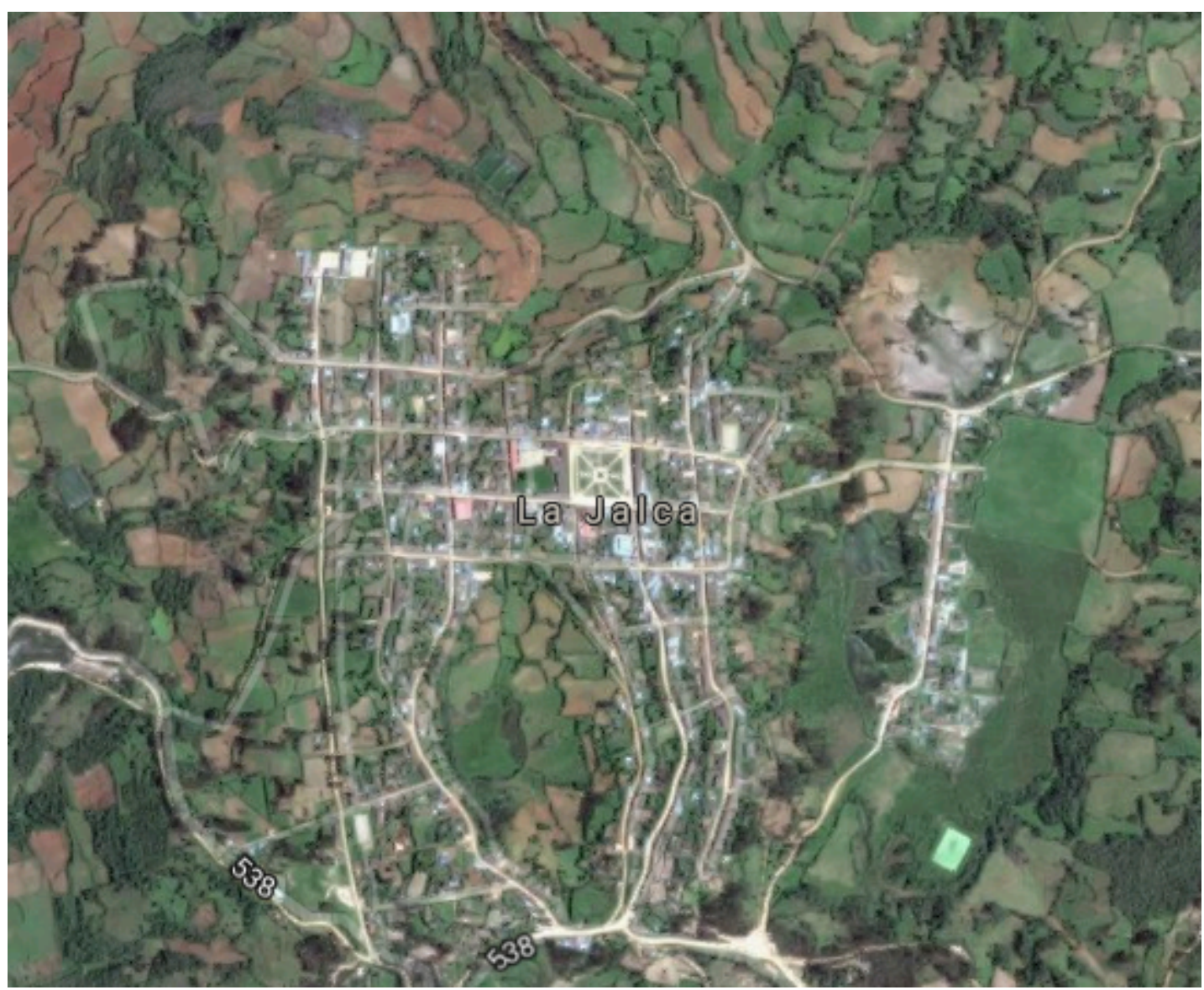

Figure 1.2 La Jalca and surrounding farms. Source: Google Maps 2016.

The predominant economic activity in La Jalca, like most of the Sierra, is agriculture. In the cool, relatively high elevation of the District of La Jalca Grande, potatoes, corn, and legumes are the primary agricultural products. These are destined for markets on the coast and the jungle, where these staples cannot be grown In recent years, the Peruvian government and various non-governmental organizations have begun promoting the cultivation of quinoa in places where it has fallen out of favor, including the southern highlands of the Department of Amazonas. In the three-year period from 2012 to 2014, the government of Amazonas invested S/. 2.5 million to cultivate 1400 hectares of traditional Andean crops, including quinoa. (Gobierno Regional Amazonas, 2011) 


\subsection{Quinoa in Peru}

Through a long history of domestication, more than 3000 varieties of quinoa have been developed to suit the diverse microclimates of the Andes. From the dry, low-lying plains of Chile, to the wet, temperate valleys of Ecuador, quinoa has had an important position in the agriculture and diet of South America for centuries. Serious scientific study of quinoa began in the 1960s, but in recent decades has it been recognized for its nutritional value. The culmination of its rise in global prominence, the Food and Agriculture Organization of the United Nations declared the year 2013 "The International Year of Quinoa," celebrating the role of quinoa as "an important ally in the fight against hunger." (Bazile, 2015)

As favorable perception of quinoa as a health food is driving demand and prices upward, production is increasing. For example for the month of January 2015, the Peruvian Ministry of Agriculture and Irrigation (MINAGRI) reported a $339 \%$ increase in the production of quinoa, from 1.5 million tons in 2014 to 5.2 million tons, owing to a campaign to expand growth in the Sierra. During that period, the price per kilogram paid to the quinoa producer was estimated to be S/.5.62. At the same time, production of potatoes (price to producer per kilogram: S/.0.75), fell 8.6\%. This is attributed to farmers in the Sierra shifting cultivation from potatoes to quinoa to increase their earnings (MINAGRI, 2015). These data are consistent with my personal observations and interactions during my time in Peru. At the time of my service, farmers in La Jalca received a price of S/.0.60 S/.0.90 per kilo of potatoes, depending on the variety, quality, and size of potato, as well as the time of year. Quinoa prices for Jalquino farmers were somewhat lower, between $S / .3$ to $S / .4$. While below average, the price is considerably higher than that of potatoes, which may partially explain both top-down investment by the national and regional governments, as well as the solicitation of several communities in Amazonas, including La Jalca, for the technical assistance of NGOs and the Ministry of Agriculture in the cultivation of quinoa.

Despite these promising advances, there is one critical barrier to the wider cultivation of quinoa by smallholder farmers - the reliance on manual labor in the traditional method of harvesting. The following section serves to explain the traditional method of quinoa preparation, as practiced widely in Peru and as observed in La Jalca; to describe the 
role of technology in the improvement of quinoa production; and to identify opportunities to deploy such improvements in the specific context of La Jalca.

\subsubsection{Traditional Harvest and Post-Harvest Preparation of Quinoa}

Quinoa is a pseudocereal, belonging to the Amaranthaceae family, which includes amaranth and its Andean relatives kiwicha and cañiwa. Although it is not a true cereal, i.e. a member of the grass family Poaceae, which includes the cereal grains rice, wheat, and corn, its culinary use and physiology are very similar. As a reflection of their physical similarity, quinoa is harvested and handled in much the same way as grains such as wheat and rice. With that in mind, it is not surprising that the path to produce quinoa well beyond the subsistence level has, in some respects, paralleled that of the developed world, particularly in the realm of mechanization. This section aims to describe the current state of quinoa production, beginning with an overview of traditional techniques as practiced throughout Peru and specifically in La Jalca. It will explain how the postharvest losses and high labor inputs associated with traditional techniques limit the profitability of quinoa production. Finally, it will review the development of technologies for the improvement of the post-harvest process with particular emphasis on the threshing stage.

\section{Harvest and drying}

Quinoa has reached its maturity when its leaves begin to yellow and the seeds harden. At this stage the plant must be cut down and left to dry. In most regions of Peru, and in my personal observations in La Jalca, this was done with a sickle or sharp knife. In other parts of Peru with sandy soil, plants are not cut down, but rather the entire plant is uprooted. This practice is discouraged by agriculture extensionists, as it introduces soil and rocks into the quinoa, reducing its quality and thus its market value. After they are cut, the plants are arranged to facilitate drying. In dryer climates, this can be done in the field, whereas in La Jalca, where the dry season is much shorter, quinoa plants are brought under a covering to protect them from the possibility of rain, which can ruin the seed with mold or even cause it to sprout prematurely. 


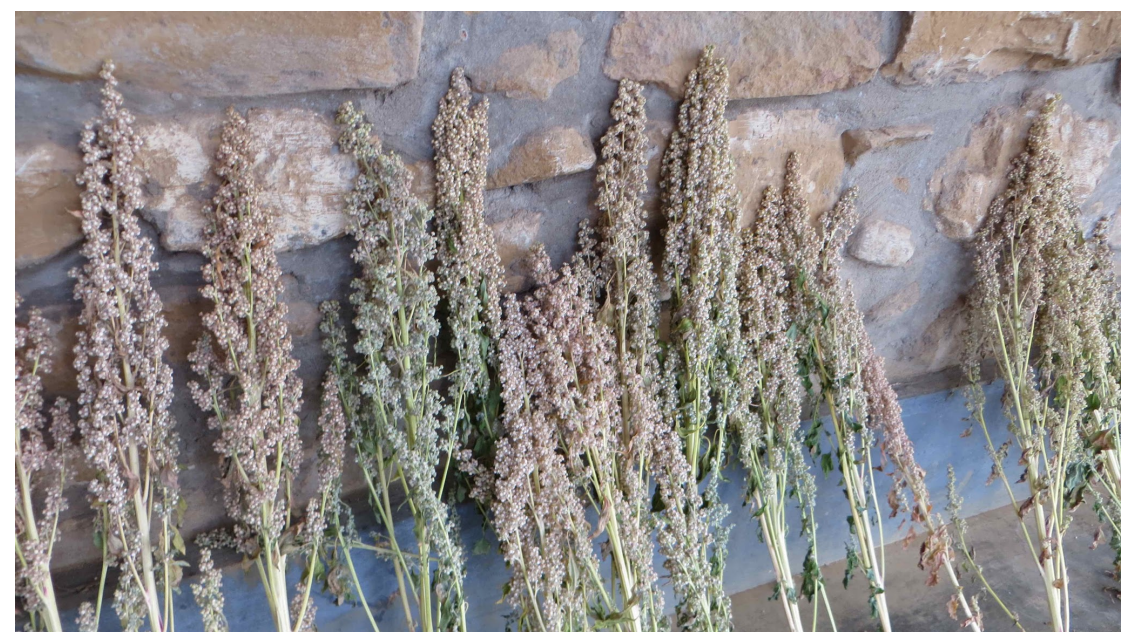

Figure 1.3 A small bundle of quinoa set out to dry.

Among the many different varieties of quinoa, some mature faster than others.

Furthermore, within the same variety, it is possible to see differences in the rate of maturity from field to field, or even plant to plant. Because of this phenomenon, in La Jalca, the quinoa harvest was carried out of the course of six weeks, with teams going into the field on a daily to weekly basis inspecting the quinoa for signs of maturity. Improved varieties of quinoa that mature more uniformly are currently in use in the southern part of Peru, where they are facilitating large-scale, mechanized production of quinoa, but I did not have direct experience with their use in Amazonas Department.

\section{Threshing}

After the plants have dried sufficiently, the dry seeds are removed from the plant in the threshing stage. Threshing is performed via either the action of friction or the action of beating. In La Jalca, I saw both methodologies being used. In the friction process, quinoa is rubbed in the hands or with the fingers to remove the grain from the stalk. In one beating process, the dry quinoa plants were gathered into a small bundle and beat against a hard surface with a tarp underneath to collect the grain. In the other, the quinoa was laid flat in a pile on the tarp, and a wooden implement like a broom handle was used to beat the grain off the plant. 


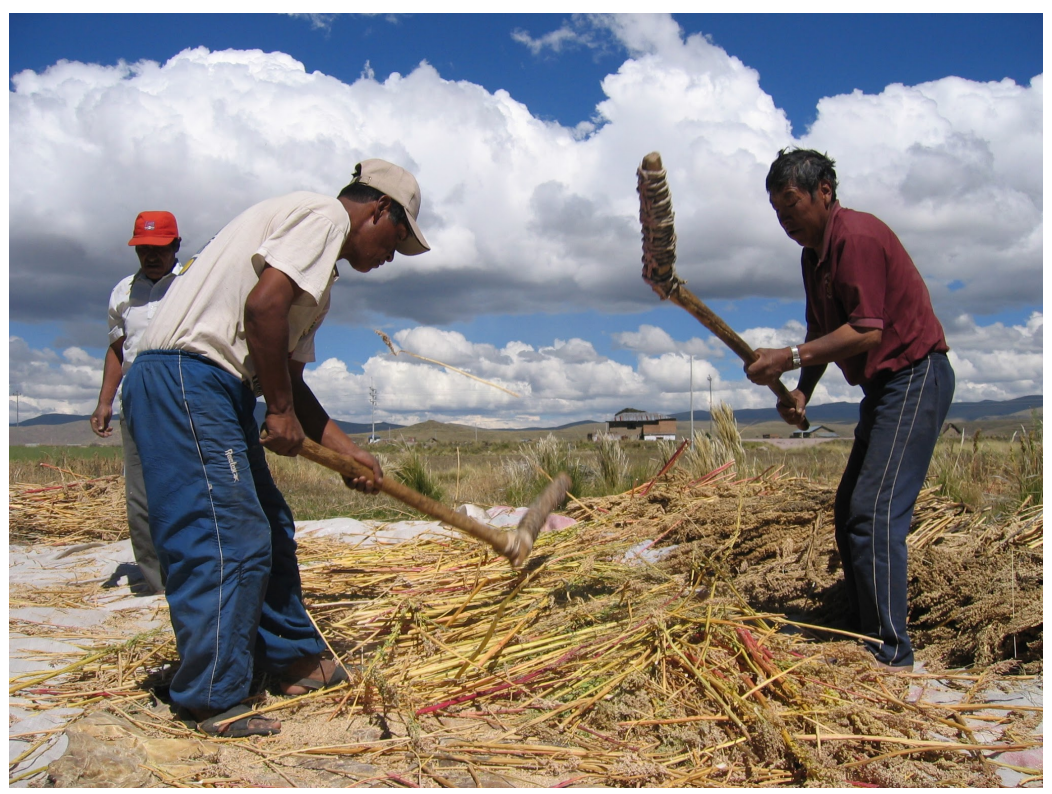

Figure 1.4 Traditional threshing of quinoa. Author: M. Hermann, Wikipedia Commons, Creative Commons, CC-BY-SA-3.0

Although not practiced in La Jalca, the use of draft animals to thresh is one of the oldest improvements over the manual process, dating back over three millennia (Hopfen, 1969). In one such method, a team of animals is allowed to tread on the piled plants, and the stomping action removes the grain from the stalk. In a more advanced method, a team of animals drags a weighted wooden sled or stone cylinder over the grain to remove it. While the use of animals is faster and less burdensome than performing manual threshing, it allows for contamination from the animals, as well as losses from the animals eating the grain.

\section{Winnowing}

Winnowing involves the separation of unwanted plant material from the threshed grain. In the traditional method, grain is gathered into a shallow container, often a basket or plastic bin, and either tossed in the air or poured slowly onto a tarp. In this way, the wind carries away lighter impurities from the heavier grain.

\section{Removal of saponins}

Quinoa are broadly classified into two varieties: bitter and sweet. In bitter varieties of quinoa, the outermost layer of the quinoa seed, the episperm, contains bitter compounds called saponins. To be made fit for human use, bitter quinoa must be cleaned, which is a 
painstaking endeavor. Sweet varieties, as the name implies, has a much lower saponin content, and after winnowing, requires no further processing prior to storage, sale, or preparation for cooking. For the smallholder farmer, this means a shorter time from harvest to market, fewer labor inputs, and, in the case of semi-mechanized production, reduced need for specialized machinery. For these reasons, agricultural extension in Peru encourages the adoption of sweet varieties of quinoa. This was the case in La Jalca where, immediately following the winnowing stage, sweet quinoa was put into 50kilogram sacks to be transported to a central processing facility on the coast. Still, for a multitude of reasons, not the least of which is tradition, bitter quinoa is the staple of many smallholder farmers throughout the Andes, and it is worth describing how it is cleaned for a complete picture of the barriers to the smallholder wishing to produce quinoa as a cash crop.

Traditional practices for the manual removal of saponins differ greatly depending on region, type of quinoa and its culinary use, and availability of water. The last of these divides saponin removal into two categories - wet methods and dry methods. In one of the simplest techniques, quinoa is polished in a large stone mortar and pestle, with the episperm being removed by the rubbing of the rough stones. In the dry version of this method, the polished quinoa may be sieved or winnowed again to remove the unwanted material, whereas wet methods involve the continuous washing of the quinoa as it is polished, or a final rinse performed after the polishing is completed. Another simple wet technique is to gather quinoa in a large cloth and suspend it a running stream or river. The bundle is periodically agitated to allow saponins to be washed downstream. In the one of the most elaborate methods, saponins are removed in a multistep process that includes roasting, rubbing, winnowing, washing, drying, re-winnowing, and re-roasting prior to storage or use (Aroni, 2015).

\subsubsection{Need for improved threshers}

Each of the aforementioned traditional methods is performed manually. Not only does this demand time and effort of smallholder farmers, but there are also economic consequences for using these methods. Relying solely on the traditional methods, an estimated $30 \%$ of total quinoa production is lost to contamination and mishandling in the post-harvest. Of these losses, $20 \%$ are attributed to the threshing process (Salas, 2003). For the small-scale Peruvian quinoa farmer, this is a considerable loss. 
The production of quinoa is a promising tool for greater food security, health, and income for farmers living in poverty in rural Peru, such as in the community of La Jalca; however, the labor-intensity and losses of the manual harvest, particularly in the threshing stage, may act as a disincentive to quinoa's wider cultivation. Taken as a whole, this reality suggests an opportunity: to help Peruvian farmers meet their need to thresh quinoa more efficiently, while reducing the effort required to do so. Observing this opportunity in La Jalca, I oversaw the design, fabrication, and operation of a prototype quinoa thresher. The design process was influenced by the human-centered design methodology, and, after returning from the field, the prototype was analyzed through a human-centered framework to determine its appropriateness for the context of La Jalca. The following chapter serves as an explanation of human-centered design and its history of application in the field of design for the developing world. 


\section{Chapter 2: Human-Centered Design}

Beginning in the 1960s with foundation of the Appropriate Technology movement, designers and engineers have advocated for the use of technology for the alleviation and ultimate elimination of global poverty. Over the following decades, success and failure alike have informed this approach to development, leading to a system of practices that will be collectively referred to as "human-centered design" in this report. The purpose of this section is to trace the evolution of human-centered design through three prominent philosophies, Appropriate Technology, Base of the Pyramid, and Human-Centered Design. Finally, after observing the strengths of each of these movements, a set of criteria will be developed which will serve as a framework through which the design of the prototype thresher will be considered.

\subsection{Appropriate Technology}

The Appropriate Technology (AT) approach is perhaps the earliest example of a formalized methodology for the design and deployment of technologies for the developing world. In 1965, E.F. Schumacher, the founder of the AT movement, established the Intermediate Technology Development Group (now known as Practical Action) for the advancement of the AT philosophy. Among its guiding principles were:

1) the development of goods and services to meet essential community needs;

2) the employment of community members in the delivery of these solutions; and

3 ) the use of local materials and financial resources in the delivery of these solutions. (Dunn, 1979)

One of the strengths of AT is its advocacy of repackaging existing technologies for the context of developing world, such as the scaling-down of agricultural implements for affordability and portability. This mode of interpreting existing technology in a new context is a form of what has been called "evolutionary innovation" and is an important means for bringing functional products into underserved markets (Castillo, 2011). In the broader context of design for development, however, AT has had somewhat limited 
success. Dogmatic interpretations of AT that insistence on hyper-local production and consumption have resulted in the failure of solutions that are too complex for local manufacture and use. Also, AT falls short of addressing non-technical desires of users and fails to consider the role of the small communities in the global context, a shortcoming that has been addressed in part by the Base of the Pyramid philosophy of economic behavior in the developing world. Furthermore, while AT acknowledges that sociocultural context can enhance the acceptability of a technology within a community, it lacks a means of gathering and processing information about this context. HCD improves on the AT philosophy by incorporating proven techniques for including the voice of the community throughout the design process.

\subsection{Base of the Pyramid}

While not precisely a methodology, the Base of the Pyramid (BoP) philosophy supplements the technical aspects of the AT system with an understanding of consumer behavior in the developing world. In the BoP perspective, low-income individuals are not simply passive recipients of intervention from more-developed countries, but rather engaged participants in the activities of consumption, production, and entrepreneurship within their local context and the greater global market (Subrahmanyan, 2008). In this view, consumer behavior extends beyond purchases that are utilitarian or simply the least-expensive alternative (Kacheba, 1997). According to the BoP model, products will be more likely to succeed if they satisfy the needs of consumers as understood within their sociocultural context, including aspirational value, long-term vs. short-term efficacy, and ease of adoption (Slaski, 2009). As a philosophy, the BoP paradigm reveals a need for products and services that do more than meet the technical requirements of a task. In contrast, the HCD methodology facilitates the design of solutions that are attractive to users precisely because they address their technical and non-technical needs.

\section{$2.3 \mathrm{HCD}$}

The HCD method, created and championed by the design firm IDEO, offers a set of exercises to inform the development of solutions that include "products, services, 
environments, organizations, and modes of interaction." (IDEO, 2009) It asserts that the critical result of the design phase is a prototype that exhibits "Desirability," that is, one that meets the needs of the end user and thus elicits their participation or purchase. To understand the needs of the user, investigation is performed through a variety of means, including formal and informal interviews, as well as immersive, experiential learning. These results guide the prototyping phase, which can involve user participation and feedback.

As a method for capturing the input and experience of the user, HCD allows the designer to consider both the technological concerns first recognized by the Appropriate Technology movement, as well as the economic concerns of Base of the Pyramid philosophy, to the ultimate end of creating a solution that truly satisfies the needs of the user. Still, despite its wide application in recent years in the developing world, HCD is not without its challenges. Because of its emphasis on co-design, it can be difficult for designers to balance pre-existing knowledge and experience against that of collaborators. Also, the apparent breadth of the technique requires additional subjectmatter-specific guidance throughout the design process to ultimately meet the standard of "desirability." In the following section, a list of criteria for desirable product design will be developed, to the ultimate end of uncovering the particular needs of Jalquino quinoa farmers.

\subsection{Criteria for Desirability in Product Design}

The application of HCD is intended to maximize the likelihood of the purchase, adoption or use of a product, that is to say, to create desirable products. However, because HCD is intended for use in a wide range of human-centered design opportunities, it does not specify the criteria of desirability. To apply HCD to the context of quinoa threshing in Jalca, it will be necessary to determine the qualities of desirable products in the agriculture setting. In one of the first analyses of the subject, Gilliam (2011) proposes a taxonomy of seven modes of failure in the design process of agricultural equipment in the developing world. Four of these (failure to meet a need, designer limitations, culture, and context) primarily relate to the capacity of the designer to understand the ecosystem in which a product is to be implemented. While these themes may inform the strategy or 
even the necessity of the development of a product, these modes of failure align more closely with inadequacies in the information gathering process, rather than the physical design of the product in question. The remaining three (complexity, usability, and manufacturability) are intimately tied to the physical product itself, and, by extension to its preceding prototypes. The question then remains, how might designers, assuming information to justify the development of a product, create and evaluate prototypes that lead to a desirable product?

In a similar vein to the work of Gilliam, Whitehead (2015) analyzes successful products implemented in the developing world, proposing six design categories prominent across 68 products. These categories encompass many design considerations previously observed, but their implementation is unique in that they are intended to be measurable, offering the designer a tool to compare and contrast existing solutions, as well as identify opportunities for improvement throughout the prototyping process. In the following section, each of these six, affinity, usability, functionality, reliability, accessibility, and value, will be defined.

\section{Affinity}

Affinity is the capacity of a product to satisfy needs of an emotional nature, such as the aspirational quality of a good. For instance, while the technical performance of two alternatives may be comparable, one may be differentiated by its aesthetic appeal, positive or negative connotations associated with its country of origin, or ergonomic preferences. Design for affinity is best guided by a thorough understanding of sociocultural context in which the product will be developed.

\section{Usability}

Usability is the capacity of the user to understand and operate a product with little explanation or instruction. This property is determined in part by the simplicity of the product at the user-product interface. Included in this is the compatibility of the product with existing norms. From this definition, design for usability will take into consideration the level of complexity of products already in use within the intended context, taking cues from prevalent and familiar modes of operation. 


\section{Functionality}

Functionality refers to the capacity of a product to meet one or more technical functions required by the user. The critical issue here is to understand the metrics of functionality that are considered most desirable to the user. For instance, a designer may needlessly pursue a solution that is precise but slow, against the needs of the user for a product that performs less efficiently but much faster.

\section{Reliability}

Reliability is the ability of a product to function normally over its useful life. It is also the quality that allows the user to restore it to functionality when it requires repair, either performing the repair themselves or being able to find skilled support and materials for its repair.

\section{Accessibility}

Accessibility refers to the ability of the user to encounter the product within their ordinary range of experiences. Where supply chains are weak or nonexistent, or where massproduced goods prohibitively expensive, to satisfy the dimension of accessibility local construction may be pursued. This dimension also refers to the ability of the product to reach its point of use, which may imply design portability and mobility.

\section{Value}

Value is the economic dimension of desirability. Value can include the initial cost to invest, the return on investment, payback period, running cost, and cost of maintenance or replacement.

While these criteria are treated as separate and independently measurable, to facilitate comparison between designs, it should be apparent that it is possible that a single design choice could influence several categories. For instance, choosing to construct a product from aluminum may make a product lighter, giving it higher accessibility or usability, but at the expense reliability, if the skill to weld aluminum is uncommon. Likewise, while several different functions may be successfully integrated into a device, it may be at the expense of ease of use. For this reason, as tools such as the desirability framework and HCD continue to develop, it is with the understanding that in many respects, design is an act of meeting user needs within a constrained environment. 
In this chapter, three approaches to design for the developing world were considered, Appropriate Technology, Base of the Pyramid, and HCD, which was shown to be a practical synthesis of the ideas of the other two. HCD was shown to be broadly applicable to design for the developing world, but limited in guidance for physical design. The broad language of desirability that is used in the HCD model was subsequently narrowed to the specific field of product design for the developing world, resulting in six criteria, consisting of affinity, usability, functionality, reliability, accessibility, and value. In the following chapter, these six dimensions of desirability will be applied to the problem of quinoa threshing in La Jalca, analyzing how the characteristics of existing technologies shape the development of an appropriate prototype. 


\section{Chapter 3: Analysis of Alternative Threshers}

In the previous chapter, a framework was presented for the analysis and development of products for the developing world. In this section, this methodology will be employed to discover desirable characteristics of threshers already in use in the developing world. First, a brief description of each alternative will be given, as well as contemporary research into the introduction of this technology to the production of quinoa, where appropriate. Finally, the specific requirements of context of La Jalca will be categorized according to the desirability framework, with each alternative or class of alternatives discussed through this lens.

\subsection{Existing Technologies}

In response to the limitations presented by traditional threshing methodologies, which have already been discussed at length earlier in this report, mechanical threshers have been developed to improve the productivity of the cultivation of grain. While most, if not all, of these were conceived as threshers of Old World crops such as rice and wheat, there have been several attempts made to adapt these for use in quinoa. In this section, two classes of threshers will be considered, those that rely on human power, and those which are motor-driven.

Human-powered threshers as a class use the same principle for grain removal, the socalled "hold-on" method. These threshers consist of a drum covered with "teeth" that is made to spin rapidly, upwards of 200 revolutions per second. While the drum is spinning, the user inserts a bundle of plants into the path of the drum and holds on the bundle as the teeth strip the grain away from the plant. To prevent grain from flying far from the point of removal, a tarp or can be placed behind the open drum, or a sheet metal covering may be included in the design (Hopfen, 1969).

Human-powered threshers can be driven by hand or foot, although the former, being more strenuous to operate, is less common. Threshers driven by foot are further divided into treadle-driven and pedal-driven. Of these, treadle-powered threshers are the older 
technology and have seen successful mass-production and adoption in rice-growing countries. Pedal-driven threshers adopt design elements of bicycles. Largely experimental as a class, they are rare; however, they are being investigated as a possible ergonomic improvement over treadle threshers (Singh, 2008).

Motor-driven threshers differ in size and functionality according to application. The simplest type of motorized thresher uses the same toothed-drum, hold-on design as human-powered threshers, but with the obvious substitution of the power source. This design offers flexibility to farmers, and one Brazilian research group has distributed plans for a hold-on drum thresher with options for treadle, motor, and tractor power (Silva, 2011).

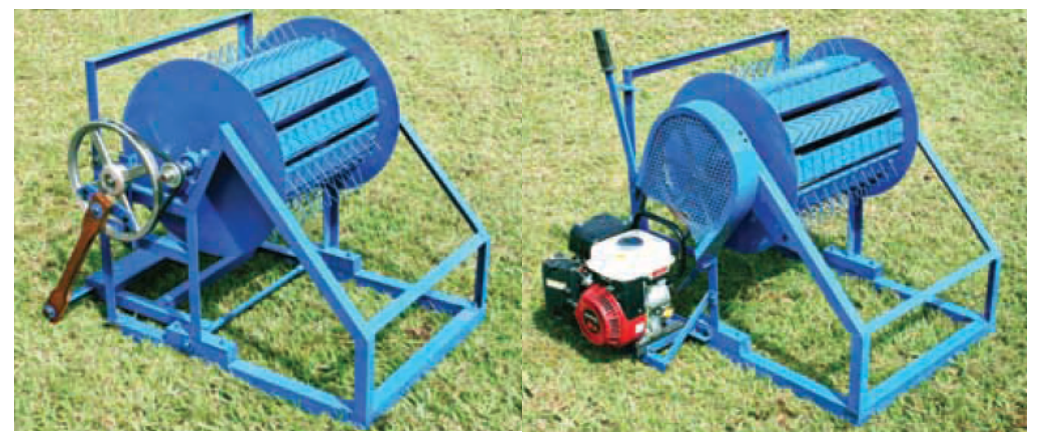

Figure 3.1 Flexible rice thresher configurations. Left, a treadle-driven design. Right, the same model adapted for motor power. Courtesy: EMBRAPA

For larger scales of production, motorized equipment trades simplicity for efficiency. Unlike human-powered threshers, these machines do not use a beating action, but rather friction to remove the grain. These threshers are known as feed-in threshers because the user inserts the entire plant into the opening of a threshing drum. Once inside the drum, millstones made of rubber or plastic rub the plant against the cylinder wall to remove the grain. The grain is separated from the larger plant matter with a sieve driven by the motor.

In the last decade, several motorized machines have been adapted for use with quinoa and have seen testing in the southern Andes. One model, a tubular thresher developed by the Bolivian NGO PROINPA for use by the small and medium scale producer, can be loaded into the back of a pickup truck and has a reported output of $95 \mathrm{~kg} / \mathrm{h}$. It runs on a 
5 horsepower gasoline motor, has a weight of around $20 \mathrm{~kg}$, and had expected minimum useful life of 10 years. This model of thresher sifts out much of the larger chaff, but smaller material must be removed by a secondary winnowing process.

(PROINPA, 2008)

A larger thresher, the Vencedor, has also been tested and promoted by PROINPA. This model, which completely integrates the winnowing step, is designed for a higher rate of production than the tubular thresher, as reflected in its larger size, a 13 horsepower motor mounted onto a frame weighing more than 1000 pounds. This machine is designed to be dragged behind a tractor or truck from threshing site to threshing site. (PROINPA, 2008)

\subsection{Comparison using HCD}

Motor-driven and human-powered threshers have been successfully used in rice growing countries at multiple scales of production. These threshers have also been shown to be suited for the technical challenge of threshing quinoa in its predominant range, the southern Andes. Through the lens of human-centered design, it is possible to see which of these alternatives, if any, could be introduced in La Jalca in the North. Moreover, it is possible that all alternatives have advantages for certain users, but not for all. The purpose of the following section is to consider the alternatives of motor-driven and human-powered threshers with respect to each area of the design of desirability: value, accessibility, functionality, reliability, usability, and affinity.

\section{Value}

Human-powered threshers, while requiring more labor than motorized threshers, have been successful in low-resource settings. In the post-World War 2 Japan, during its early industrialization, smallholder rice farmers who constituted the major part of Japanese agriculture enthusiastically adopted the relatively inexpensive treadle thresher, with a reported density of one thresher for every 3 hectares (Hopfen, 1969). In modern day India, treadle threshers remain popular with rice producers of low economic means.

Motor-driven threshers require fewer labor inputs than human-powered ones, but they are more expensive. In addition to the initial cost of the machine, the running cost of 
gasoline, diesel, or electricity must be considered, as well as that of maintenance or repair. The higher cost need not absolutely disqualify a thresher as appropriate. Where labor is scarce or relatively expensive compared to fuel, the investment in a motorized solution may be appealing. There remains, however, the question of the initial purchase of the machine. In the southern Andes, capital is low and credit is scarce, and the high cost of motorized threshers has slowed their adoption (Aroni, 2015). It is equally likely that in La Jalca, which is economically similar to the South, the purchase of a motorized thresher would be the exception rather than the rule. A design for the context of La Jalca, it follows, should be relatively inexpensive.

\section{Accessibility}

In Peru, geography defines accessibility. For instance, the terrain of the Altiplano region of southern Peru is characterized by gentle hills and plains. Here, tractors and pickup trucks can easily haul motorized threshers from small plot to small plot, or across large, open expanses of land. Large-scale quinoa producers also benefit from this geography, as it enables the use of combine harvesters. Without a doubt, this is appropriate design for flat areas or those with abundant road access. La Jalca, however, is neither of these, and it severely limits the usefulness of motorized threshers.

A one-lane dirt road connects the town of La Jalca to the paved highway which is the artery of the southern half of the Department of Amazonas. Depicted in red in Figure 3.6, below, this road passes through the core of the town of La Jalca, which is enclosed within the green circle. Apart from these, the road and the town center, there is no automobile access. Because of this, many smaller communities in the district are not connected to the highway. Moreover, a very small minority of farms have direct access to this important line of transportation. Instead, travel between communities and to farms and fields is done the walking paths, shown in yellow. 


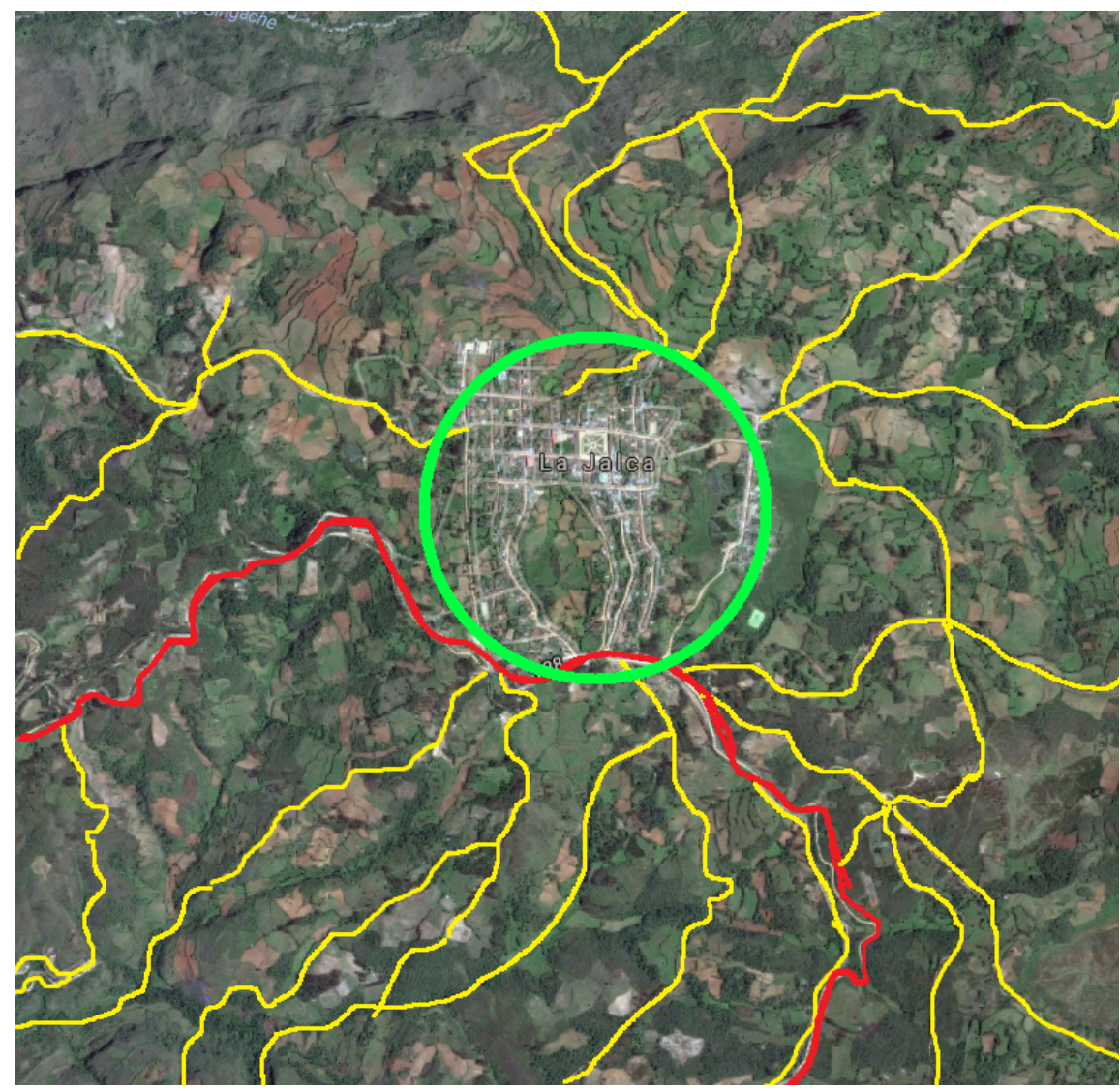

Figure 3.2: Map of La Jalca. The green circle and red line represent the extent of automobile access, while the yellow trails are the primary mode of daily travel for Jalquino farmers. Adapted from Google Maps 2016.

From personal experience, these trails are steep and narrow. The movement of goods along these trails is limited to what can be personally carried or put on horses. So, while a heavy motorized thresher can theoretically be brought to the district of La Jalca, it will only be usable by a minority of farmers whose fields are adjacent to the highway. On the other hand, many human-powered threshers are designed to be light and portable. These would have a much greater usefulness in this context where plots are small, dispersed, and difficult to reach.

\section{Functionality}

From a purely technical perspective, both motorized and human-powered threshers improve upon manual methods. In a head-to-head comparison of manual and mechanized rice threshing, the Selco Foundation showed that treadle-powered and motorized threshers out-performed manual threshing for production in kilograms per 
person per hour. In this study, an open-drum thresher with a $1 / 2$ horsepower engine was up to twice as fast as manual threshing, while a 4 horsepower feed-in thresher was up to three times as fast (Selco Foundation, 2013).

Larger threshers that combine the two functions of threshing and winnowing produce very clean grain as the end product. This level of functionality is important in reducing contamination and the need for a separate winnowing machine, but it compromises on energy flexibility. To run these two functions in one machine requires more power than can be provided by a single human operator. Although they are restricted to one function, and output quality is less, open-drum threshers such as the Embrapa model can be adapted for use with a stand-alone motor, a tractor, or with human power. In the context of La Jalca, this energy flexibility would be accommodating to users of different income levels, with the option to upgrade over time.

\section{Reliability}

The first consideration of reliability is ability of the product to work on a day-to-day basis. Longevity motorized and human-powered threshers alike, the design process has always been informed by the need for robustness. Although longevity has been a consideration for all types of threshers, another facet of reliability, repairability, presents an important difference between the two.

Repairability in La Jalca is a question of available materials and skills. Because La Jalca has metalworkers and woodworkers, it is likely that minor damage to either a motorized or human-powered thresher can be repaired using locally-available materials. Where specialized parts are required, such as those of a motorized thresher, weak supply chains may delay or even prevent repair. The simplicity of the mechanism of an opendrum thresher lends itself not only to repairability, but also to the complete construction of the machine by local craftsmen. In this way, repair can be carried out by those who are most familiar with the design and function of the machine, and with skills to keep it running.

In the specific case of human-powered threshers, the ability to find replacement parts also informs the type of machine built and the way that energy is transmitted. Commercially produced treadle threshers use gears or a belt and pulley to connect the 
treadle to the drum. The robustness and ubiquity of these parts in an industrial setting make them very appealing for this use. In the case of locally produced treadle threshers, bicycle sprockets and chains have demonstrated success as alternatives to gears and pulleys (ITDG, 1985). Taking advantage of bicycle parts can enhance reliability, but only in places where they are inexpensive or relatively common. In the town of La Jalca itself, bicycles are not terribly common, but they are popular in nearby communities and in the regional capital. While it may be possible to use bicycle parts, the capacity of local expertise in their application will have to be assessed.

\section{Usability}

From a usability standpoint, there is little difference among the several types of motorized threshers. Their operating principle is relatively straightforward from the perspective of the user, requiring only that sheaves of quinoa be inserted in the drum and clean quinoa collected from the outlet. While specific details of calibration may need to be taken into account, on the surface this does not seem to be incompatible with the Jalquino experience of operating mechanical equipment.

For human-powered threshers there are a few design decisions to be made for improved usability. The choice between pedal- and treadle-drive drives is influenced by several factors, including availability of parts and ease of construction, but in the case of La Jalca cultural factors may be more important. In some parts of the world it is considered culturally inappropriate for women to operate a bicycle. In La Jalca, the rarity of bicycles altogether makes it difficult to determine if there are gender norms surrounding their use. Still, the rarity of bicycles calls into scrutiny a design that relies on a relatively foreign mode of operation. A more culturally acceptable solution would be a treadle, as there is already precedent for its use in La Jalca. Motorless, treadle sewing machines are commonplace in La Jalca, which has a centuries-old tradition of artisanal textiles. Although weaving and knitting are associated with the female role in La Jalca, sewing is undertaken by both genders, and men and women alike operate treadle machines. This adjacent technology could easily be migrated into a human-powered thresher.

\section{Affinity}

It is relatively simple to compare the monetary value of improved quinoa production, but assessing the subtle, intangible value of choosing one thresher over another, or any 
thresher over the traditional practice is more difficult. Because quinoa is not widely cultivated the northern Andes, it is possible that adoption rates of quinoa at large are slowed by an adherence to traditional crops and overall risk aversion. From personal experience, even among farmers of traditional crops such as potatoes and corn, there is an openness to new technologies and techniques, running the gamut of chemical fertilizers to organic compost and worm castings. Given that current quinoa farmers have already crossed the threshold of early adoption, doing so even while understand that the labor requirement is much more than other crops, it may be possible that this community would also be open to the purchase or construction of a mechanized solution.

\subsection{Summary of Design criteria}

Taking all of the previous analysis into consideration, certain design elements can be gleaned from existing solutions. From the initial findings, portability and affordability would seem to be the most important features of a successful thresher in La Jalca, which implies one that does not rely on a heavy, expensive motor, that is, a humanpowered thresher. With respect to cultural norms, a treadle-powered thresher would be preferable to a pedal drive. The current lack of a supply chain for a mass-produced thresher would suggest local manufacture over purchase. Local manufacture would also lend itself well to repairability and locally-informed design and customization, as well as the ability to apply iterative prototyping. 


\section{Chapter 4: Design, Construction and Demonstration of a Prototype}

Analysis of existing threshing solutions using the desirability criteria suggests that a portable treadle-driven thresher would be well suited to the requirements of Jalquino farmers. However, given the obstacles for obtaining a commercially available thresher with these features, local manufacture was proposed for the construction a prototype capable of threshing quinoa. Drawing inspiration from similar projects that had been executed in the field, an initial design was proposed, bearing in mind the skill of local craftsmen and the materials available to them. Once it was determined that local construction yielded an operable prototype thresher, it was used to process quinoa. This section serves to describe the process undertaken from design to demonstration, to address some of the challenges encountered in the prototyping phase, and to suggest the ways in which the prototype may be refined in subsequent designs, with respect to the desirability criteria.

\subsection{Existing designs}

The first step of this process was to seek out existing designs, which proved to be difficult. Images and video of commercial threshers are relatively common, but detailed plans for their construction are practically non-existent. Furthermore, there is relatively little academic literature on the use of treadle-driven threshers. In the course of research, three examples were encountered of threshers that were specifically constructed in the field to assist smallholder farmers. In the following section, each of these will be presented, in no particular order of importance. It will be explained how each of these designs reflects the environment for which it was created, and how each of them contributed to the design of the quinoa thresher developed for La Jalca.

The first is a bicycle-powered wheat thresher, which was constructed by a Peace Corps Volunteer in Malawi. This design has a few distinguishing features. First, a bicycle in its entirety was used in its construction. It is essentially a stationary bike whose rider 
powers the spinning drum. The drum itself is also constructed of bicycle parts, with rims used for the sides of the drum. The advantage of this is the ability to directly power the drum from the bicycle, without resorting to major modifications to neither the bike chasis nor the chain drive, apart from extending its length. In consideration to each of these choices, where bicycle parts are common, this feature may more convenient from financial perspective, enhancing its value, as well as a reduction of complexity, enhancing usability. The machine itself is contained with a box of plywood which contains the grain after threshing.

Another notable design is that of the treadle-powered thresher developed by Intermediate Technology Development Group (now Practical Action). This thresher was intended to replicate the functionality of factory-built rice threshers but with an emphasis on locally-available parts, using a bicycle chain and sprocket in place of gears or pulleys, as well as a wooden frame in place metal. This model is driven by a treadle made of mild steel. While extensive experimental testing of this model was not carried out, it was suggested that a team of 3-5 people (one operating the machine as the others provide bundles of grain) could thresh approximately $115 \mathrm{~kg}$ per hour [42]. This design is interesting in that only specific bicycle parts are used, rather than the entire bicycle, which made possible through the use of modular, interchangeable hardware more common to older bicycles.

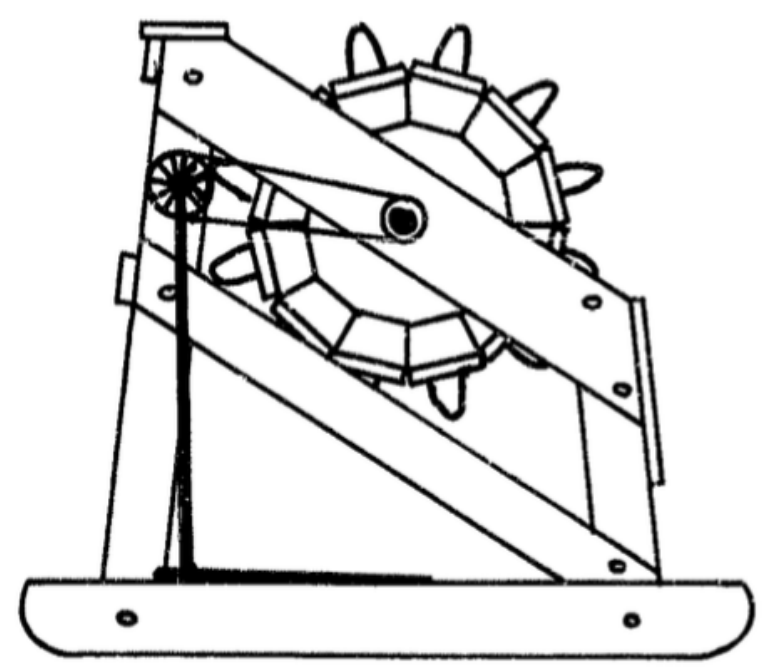

Figure 4.1: Side view of ITDG thresher. The uses stands on the taller side of the machine, depressing the treadle by foot. Courtesy: Practical Action 
The last of threshers that influenced the design was that of the Brazilian Agriculture Research Corporation (EMBRAPA) that was first seen in the previous chapter. This machine, pictured below in Figure 4.3, was designed in such a way that small-scale rice farmers of Brazil could easily adapt it to their energy needs. It features off-the-shelf parts such as bushings, bearings, and fasteners. The frame itself comprised of welded angle iron, with some wooden elements, and the drum is made from standard lumber. Unlike the previous two designs, this thresher uses a belt and pulley system. These design decisions allow for standardized, replicable thresher, but rely on affordable access to these materials for its construction or repair.

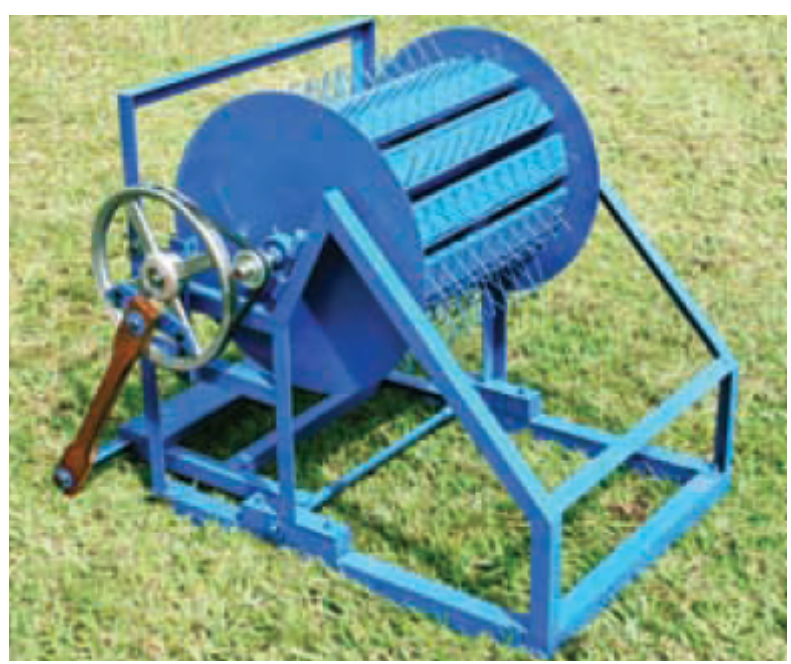

Figure 4.2: Wood and metal thresher. Courtesy: EMBRAPA

With the intention of developing a functioning prototype, but lacking the resources to purchase specialized hardware, such as bearings and a belt and pulley, alternative sources for prototyping materials were sought. In the course of gathering resources, two mountain bikes were donated by Peace Corps Peru that would have otherwise been discarded. As a result, the design and construction of the thresher were carried out to maximize the use of these free materials, while still satisfying the needs of Jalquino farmers as suggested by human-centered design. The end result was a prototype that adapted elements from each of the aforementioned threshers, as illustrated below in Figure 4.4. 


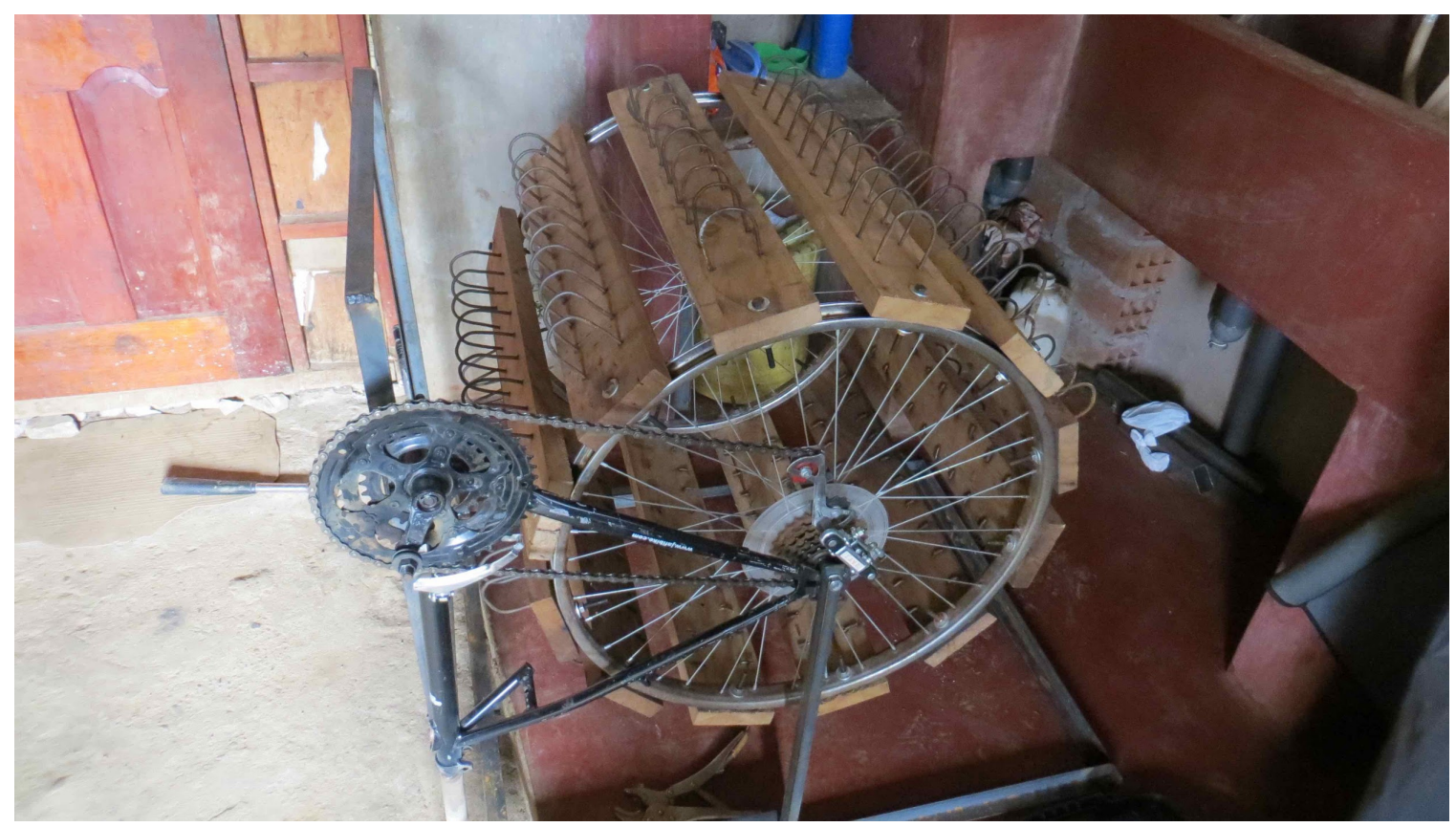

Figure 4.3: Finalized prototype

Similar to the bicycle-driven wheat thresher, the drum is constructed using the rims of one of the donated bicycles, which left intact the front and rear sprockets, and also eliminated the need to purchase large pieces of wood or metal that would have otherwise been used for the sides of the drum. Because a pedal-driven thresher was previously determined to be culturally questionable, the body of bicycle was modified in such a way to be operated by treadle, as in the ITDG model. Last, given the availability and affordability of angle iron, the presence of local welders in La Jalca, and the relative lightness of the material, metal was for the chasis, rather than wood, as in the EMBRAPA example.

\subsection{Construction of the prototype}

The prototype can be described as three separate parts or subsystems: the drum, the chassis, and the treadle. The drum consisted of twelve slats covered with wire loops, which strip the grain from the stalk. The slats of the threshing drum were constructed from eucalyptus planks, provided by a woodworker in La Jalca who also generously donated his labor to the project. Large planks were cut to a length of 24 inches, as suggested by the ITDG plans. Holes were drilled for the insertion of the wire loops at a 
spacing of 2 inches. Although nails or straight pieces of wire would perform the job of threshing as well as wire loops, and would require less effort to manufacture, loops are safer for the user, during operation and handling of the drum. Six of the planks received 10 loops, while the other six were given nine. This is to insure that the wire loops are offset from one another, to allow the quinoa plant more opportunities to collide with the loops. This offset can be seen in Figure 4.4, with tooth of every other board lining up with the gap of the one in front.

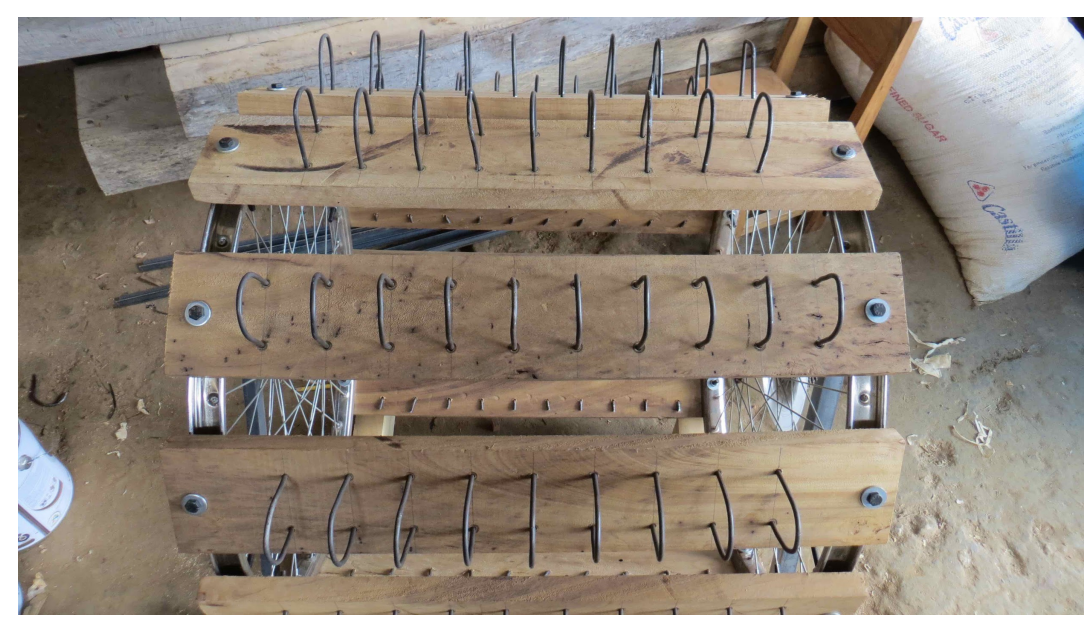

Figure 4.4: Fully assembled drum demonstrating the offset of teeth of every other plank.

To begin the assembly of each of planks, wire loops were cut to nine inches in length. The loops were made to be two inches wide at the base and stand at a height of three inches from the surface of the drum. These were bent by hand before inserting them into the slats. The installation of the wire loops proved to be challenging, and required experimentation to develop a reliable method of assembly. While the ITDG plans suggest that the holes be undersized and the wires hammered in place, this method was difficult in practice, as it resulted in misshapen and bent loops that required straightening after installation. To reduce the number of these misshapen loops, a custom drill bit of the exact diameter of the wire was made by shaping a nail on a benchtop grinding wheel. Holes drilled with this bit resulted in a tighter fit, but not so tight as to prevent insertion of the loops. To further guarantee that the wires would stay in place, the ends of the loops were doubled over with a hammer. After all of the loops were installed, the slats were mounted to the rims with bolts. 


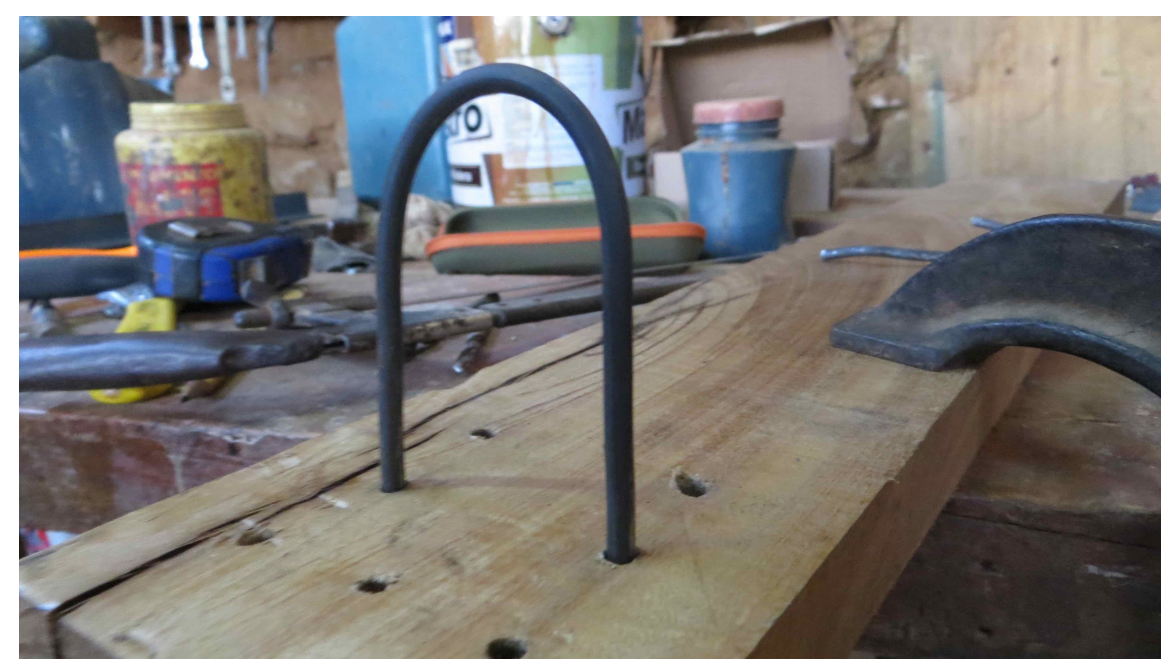

Figure 4.5: A single loop ready for installation.

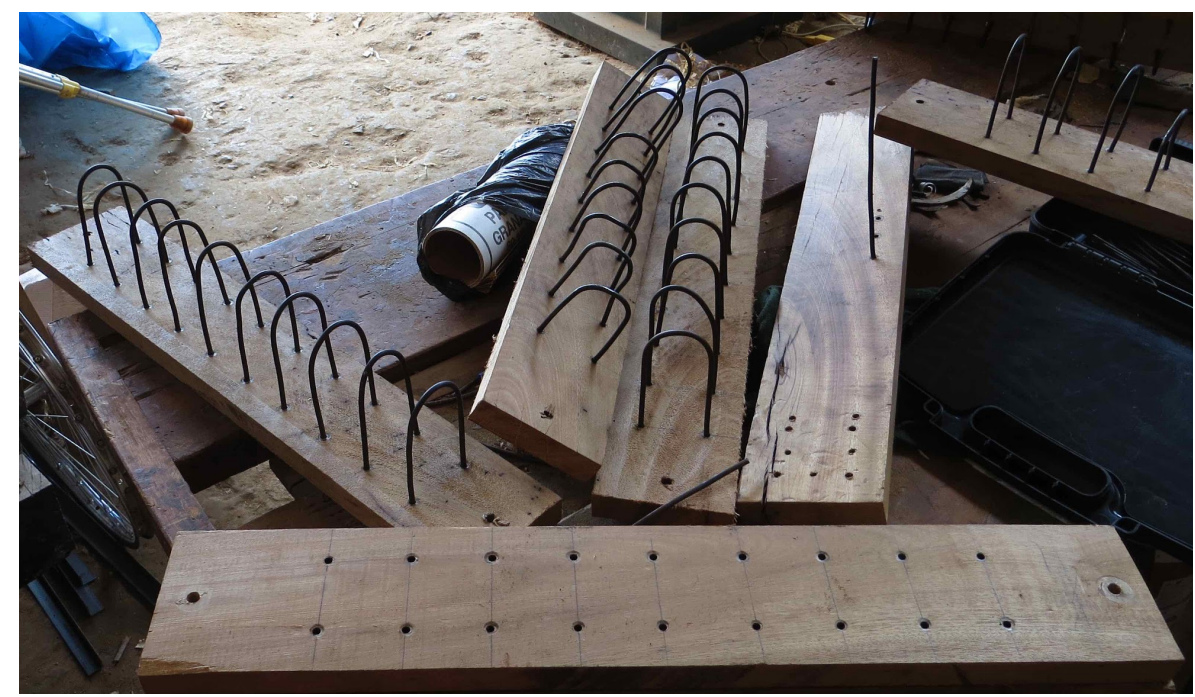

Figure 4.6: Planks in various states of installation.

In Figure 4.5, a well-formed loop is shown. When the holes were sized correctly, a gentle tap of the hammer would put the loop into place. Figure 4.6 shows planks in different states of placing the loops. The loops on the leftmost plank are not completely inserted, and the shape of the loops is relatively uniform. The two planks in the center of the figure have the loops completely inserted. Of these, the plank on the left has several loops that resisted insertion, and more forceful use of the hammer was required. These loops were then bent back into shape using the claw of the hammer. Finally, Figure 4.7 shows the underside of one of these planks where the loops were bent. 


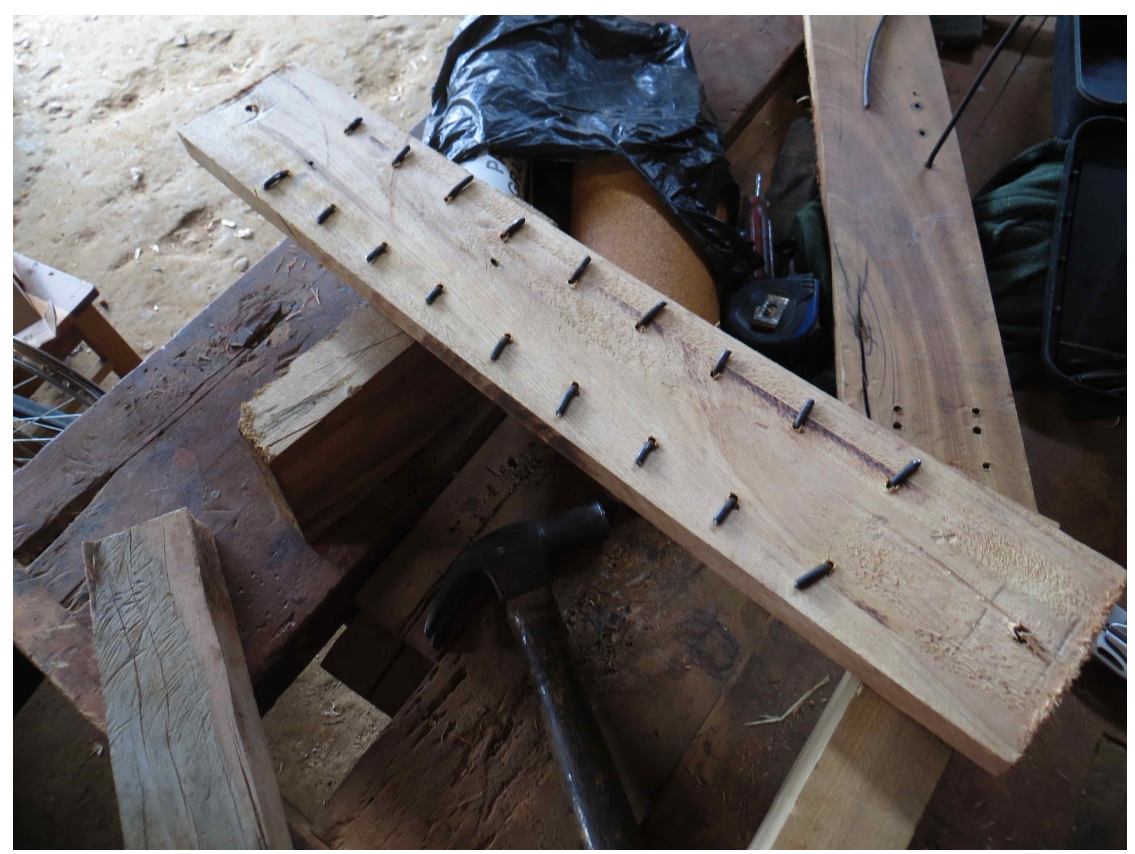

Figure 4.7: Underside of a completed plank.

The first step in the construction of the frame was to determine how much of the bicycle would be saved, as this would have consequences in the size of the chassis, the placement of the drum, and the geometry of the treadle. The critical parts of the frame for the treadle mechanism were those associated with the sprockets in front and rear of the bicycle, that is, the bottom bracket shell and the dropouts respectively. This meant that the top tube, head tube, and downtube could be inconsequentially removed from the rest of the frame, which was done with a hacksaw. This is shown in Figure 4.8, with the yellow dashed line representing the cut line, and everything to the left of that, in the dashed region, was discarded. 


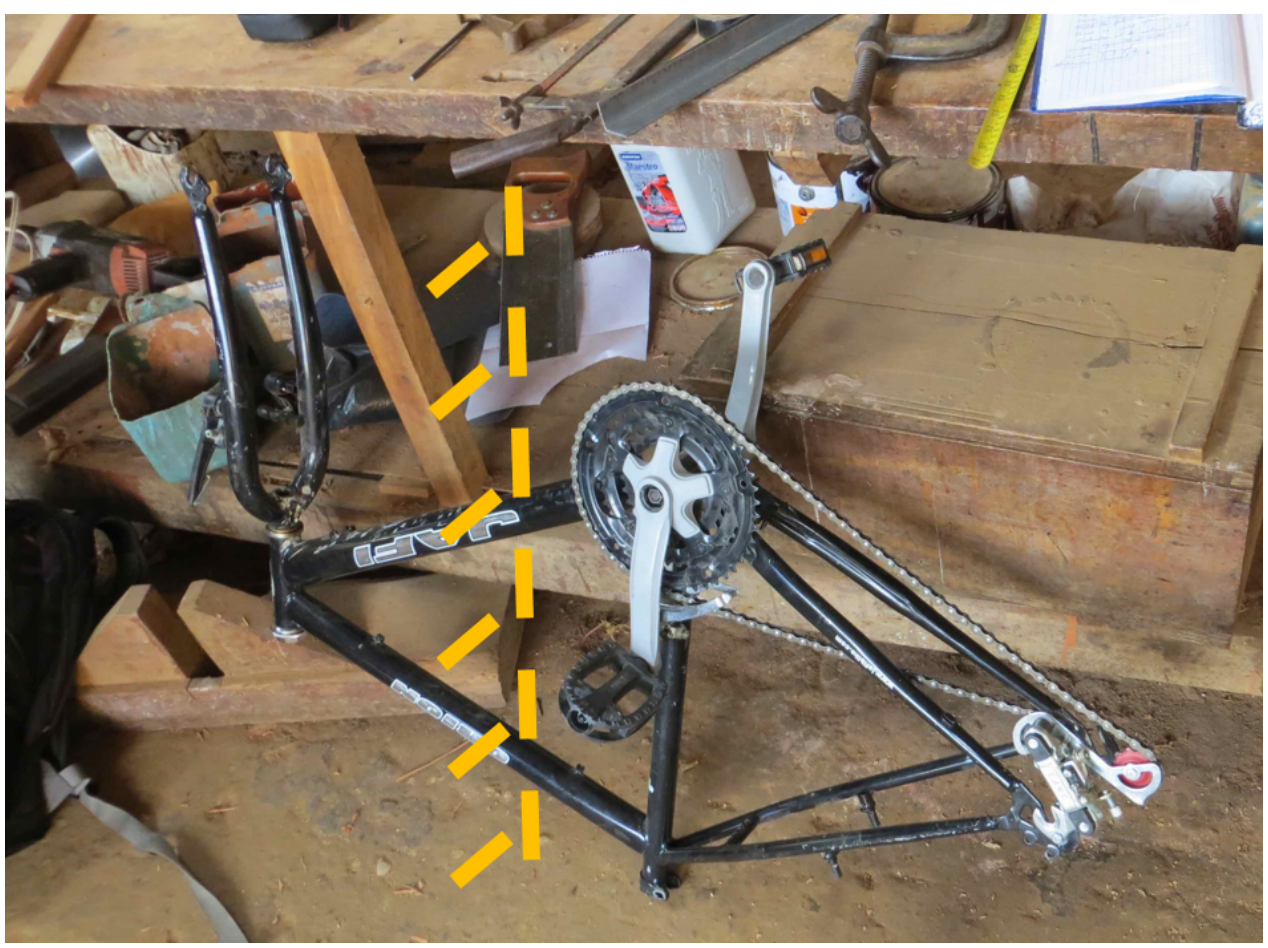

Figure 4.8: Dashed line showing portion of the bicycle frame that was removed.

For the construction of the frame, this section of bicycle was oriented upside down, with the dropout opening vertically, as shown above in Figure 4.8. This served a dual purpose. First, this position keeps the crankset (the gears at the pedals) off the ground without needing to modify the bottom bracket shell by welding, which could potentially damage the bottom bracket beyond repair. Second, by arranging the dropout upside down, the drum can be placed in without fear of it falling off the frame. To accommodate the width of the drum, one of the dropouts was removed. The height of the drum was set so that the outside edge of the drum was roughly waist high, which is consistent with both factory-made and artisanal threshers. The drum is supported by two vertical members which are welded to the rectangular base of the chassis. To provide mounting points for the drum, a hole was made in each of the vertical members on a drill press, one inch from the top of the support. Inserted into the frame, the axles on the bicycle hubs are locked in place with a nut. The drum then rotates on the bearings of the hub.

After the positioning of the drum had been resolved, it was possible to orient the partial bicycle frame with respect to the rest of the chassis. A critical element of the design was to make sure that the front and rear sprockets were aligned before welding everything in place. When the position of the drum had been fixed, several low-speed practice runs of 
the chain-and-sprocket mechanism were undertaken to see that the chain would not jump off of either one of the cogs of the cassette or the chainring. With that alignment resolved, it was decided that, for simplification of construction of the chassis, the bicycle frame was arranged so that the seat tube was ninety degrees relative to the ground. To accomplish this, the seat tube was extended with a piece of steel tubing. It was then welded to the base of the chassis. Figure 4.9 shows drum and frame fully assembled, but still without the necessary modifications performed for the installation of the treadle. The final addition to the chassis was a horizontal bar to permit the user a means of support during operation. This addition can be observed in Figure 4.10.

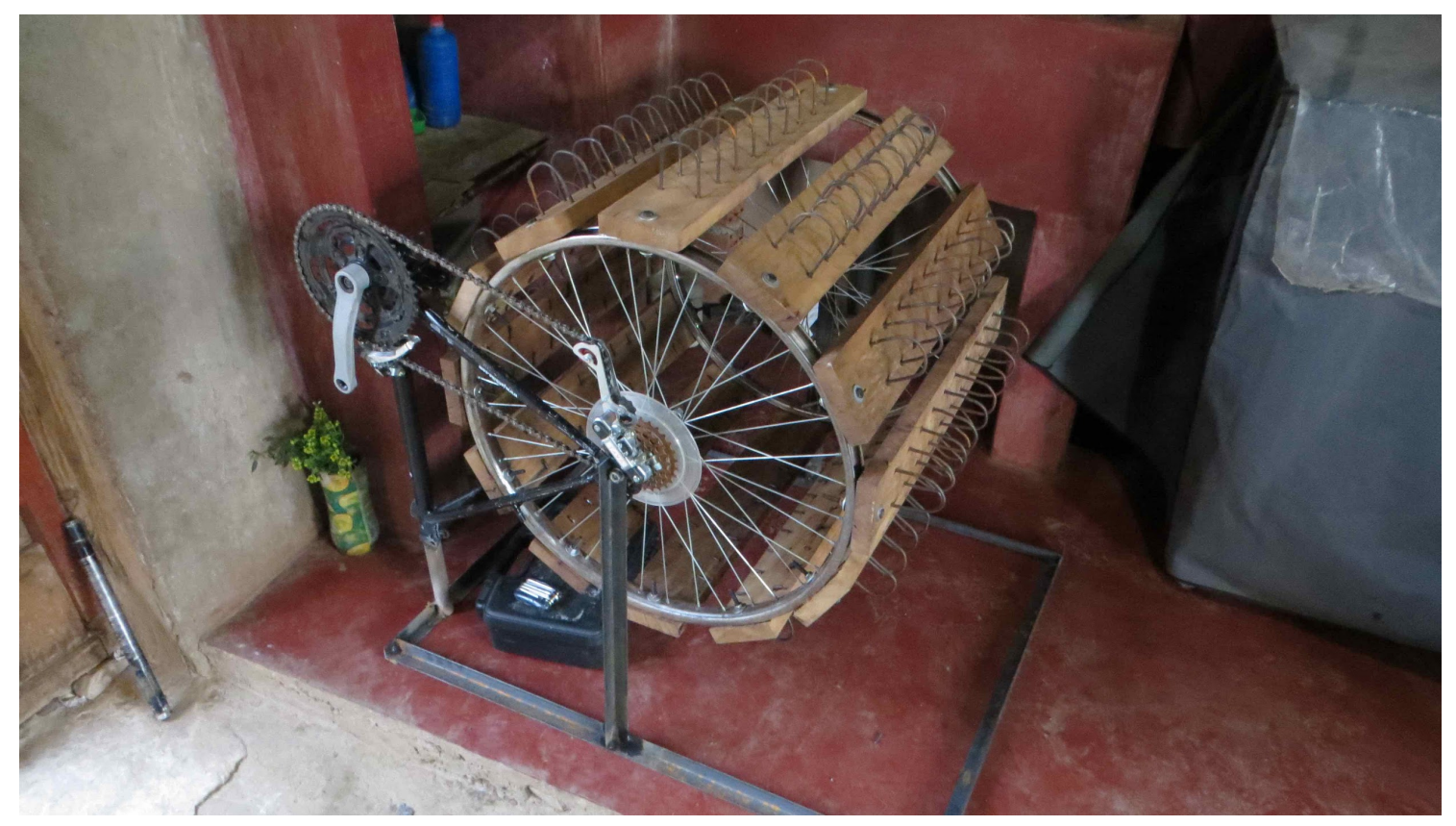

Figure 4.9: The drum seated into the frame. Note to the left the extension of the seat post so that it could stand normal to the ground. The bearings of the bicycle wheels bolt into holes in the vertical member on either side.

To function correctly, it was necessary to modify the freewheel of what had previously been the rear wheel of one of the mountain bikes. The freewheel mechanism is made of two parts that rotate independently of one another. On a bicycle, this allows the rear wheel to continue spinning without the riding peddling. In the case of the treadle thresher, this mechanism would prevent the treadle from returning for the next power stroke, and would effectively make the machine useless. To make the treadle work 
properly, the two independent parts of the freewheel were spot-welded together, forcing these sprockets or cogs to rotate with the drum at all times.

The treadle assembly converts the reciprocating up-and-down motion of the treadle to rotational motion of the cylinder. The treadle is a frame of angle iron welded together and bolted to the main body of the machine. A linkage connects the treadle to the crank arm of the bicycle, which has been cut to a two-inch length, to reduce the displacement of the treadle to a 4-inch stroke, as suggested by ITDG to provide comfortable operation. This modification to the crank arm can be seen in Figure 4.10. As with normal bicycle operation, the rear sprocket, which is now a component of the drum, is driven via the chain, which is attached to the chainring of the crank. Because shifting gears is unnecessary for this machine, the derailleur and chain tensioner were eventually removed and the chain was shortened so that it could run at the highest gear ratio of 3:1 (corresponding to the 48-tooth chainring and the 16-tooth cog).

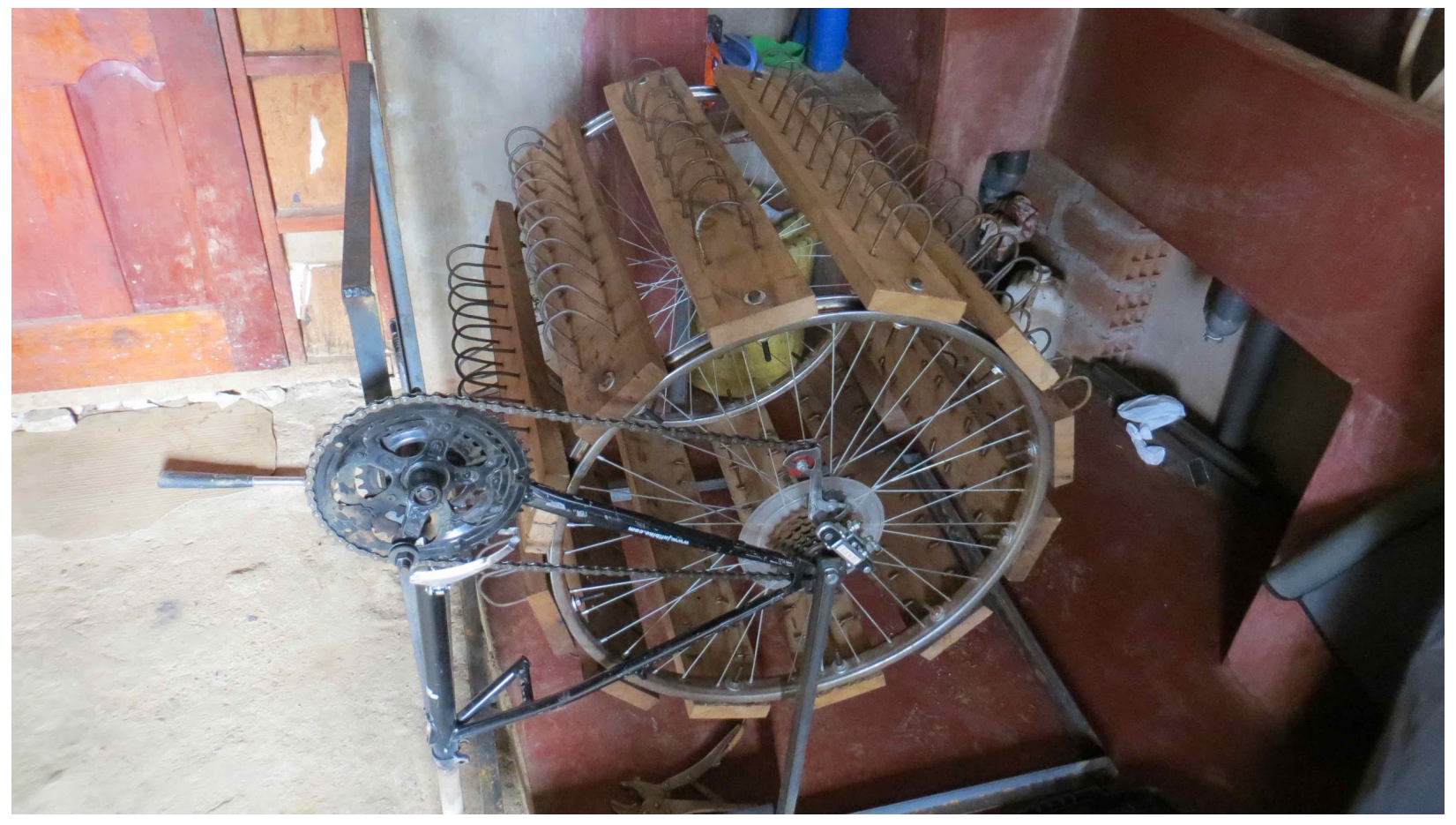

Figure 4.10: Thresher with crank arm shortened to 2 inches in length. Note the support bar above the sprockets to the left. 


\subsection{Field Demonstration}

After the thresher was completed, it was used to thresh quinoa in a small field in La Jalca belonging to one of the members of the cooperative. While it had been hoped that a rigorous series of performance tests would be conducted through the harvest season, delays in the design process and construction only allowed for a more limited demonstration, in which members of the quinoa cooperative and myself were able to observe and operate the prototype thresher.

The thresher was carried from the workshop to the place where threshing would be performed. During construction, there were concerns about the portability of the thresher. In its disassembled state, the drum in particular was cumbersome, owing to its heavy construction and lack of handholds for the user. When the drum was installed into the machine and the entire assembly moved as a whole, this proved to be a non-issue. Despite the extra weight, the ability grab the bottom of the frame allowed for reasonable transportation to the demonstration site by two people.

The thresher was operated with the participation of members of the quinoa cooperative, as well as other interested parties of the community. To begin, the treadle was depressed and the drum simultaneously given a push start to rotate away from the user. With a steady rhythm, the drum was brought up to speed until it reached its apparent maximum. Sheaves of quinoa were then placed in the path of the drum, which resulted in quinoa flying off of the drum with surprising velocity. 


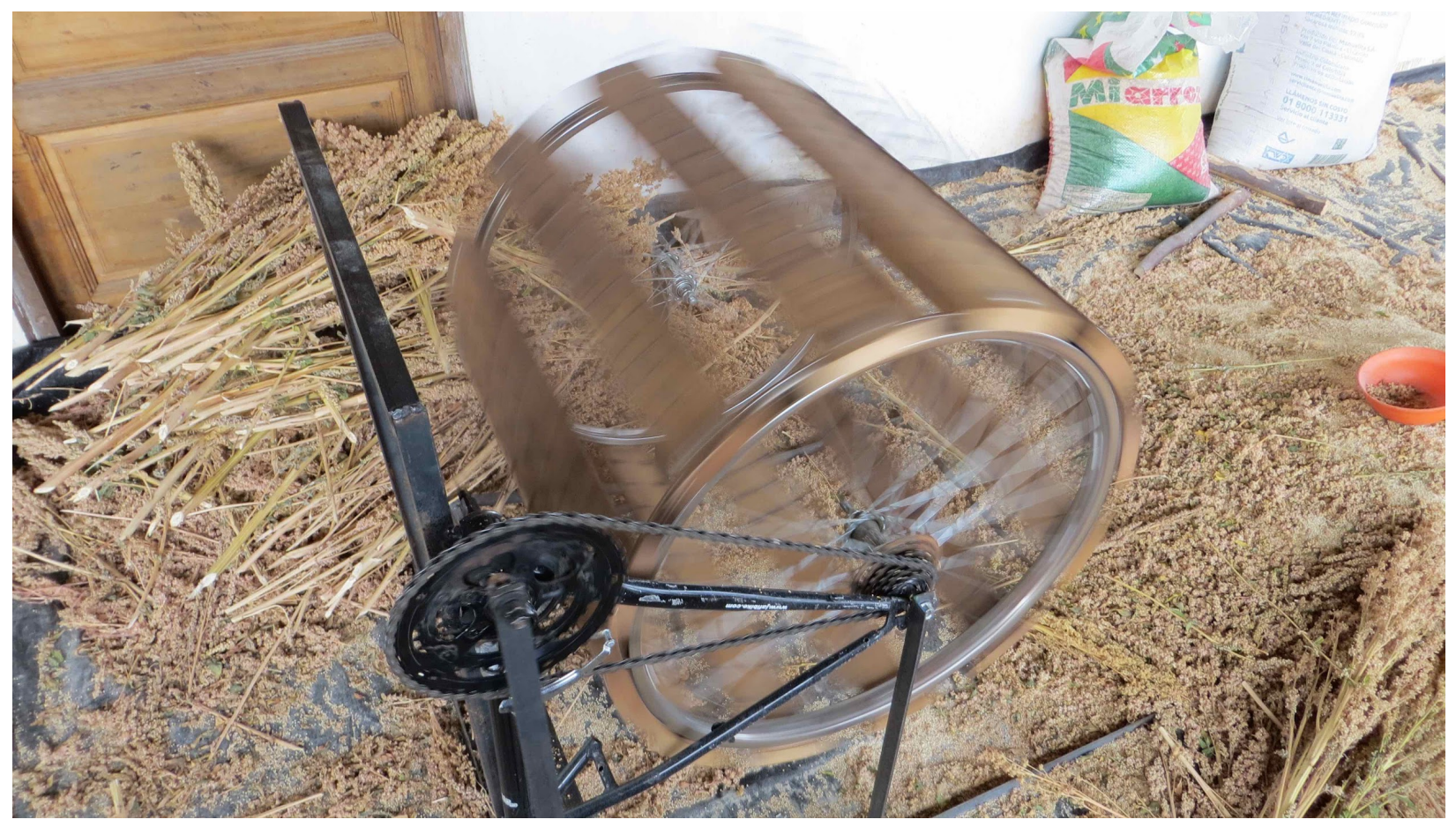

Figure 4.11: Demonstrating the functionality of the completed prototype. To the left, quinoa stacked, ready for threshing. To the right, scattered debris on the threshing floor.

\subsection{Discussion}

Because of the unanticipated delays in the development of the prototype, quantitative data regarding its performance during operation were not gathered, and require further study. Nevertheless, the construction and demonstration as performed in the field do provide interesting information that suggests a direction of improving upon the current design. First, the experience reinforced the need for co-design in the prototyping phase. Although several resources were consulted in the development of the prototype, none was a comprehensive guide to the construction of a treadle thresher, nor were they instructive on how this technology may be adapted in Peruvian culture. This constraint necessitated close collaboration between the local craftsmen and myself as the designer and engineer. Second, the development of the prototype thresher offers insights into the capacity of local craftsmen to produce a desirable thresher where it would otherwise be unavailable. 


\subsection{Design and desirability}

Although no formal experiments were conducted during the testing of the first prototype, observations during construction and demonstration suggest alterations to increase the desirability of this product. Here, improvements to the design of the prototype will be proposed, with consideration how these might enhance a particular element of desirability. Because no observation of the aesthetic or emotional qualities was undertaken, the dimension of affinity will be omitted.

\section{Functionality}

On the dimension of functionality, there are some opportunities for improving the functionality of the prototype, primarily relating to the drive mechanism. During operation, the bicycle chain slipped from the smallest rear cog to the second smallest, a drop from a 3:1 gear ratio to a 2.67:1 gear ratio. This resulted in an immediate $11 \%$ reduction in the tangential velocity of the drum. While the relationship between tangential velocity and threshing capacity is uncertain and requires further testing, it may be safely inferred that subsequent designs operate at a single, optimal speed for threshing quinoa. If a bicyclebased design is carried out in the future, care should be taken to keep the chain from jumping gears, by adding a means for keeping tension on the chain and by taking care that the sprockets are well aligned during construction. Given the fastidious nature of this prescription, a more simple solution may be the use of meshed gears or a belt and pulley to transmit power.

\section{Accessibility}

To the question of accessibility, there are two considerations. The first of these is the question of whether this product, i.e. the treadle thresher could be made readily available for use in the community of La Jalca. Given the successful construction of a functional, if flawed, prototype by local craftsmen, this would seem to be within reason, although further investigation in the sustainable, cost-effective implementation of such an enterprise would require further investigation. The second facet of accessibility, portability, could easily be enhanced in a second prototype. If bicycle parts are altogether abandoned in subsequent designs, the diameter of the drum could be 
reduced by half. Likewise, it was noted during operation a significant portion of the surface area of the threshing drum is unused, and could likely be reduced. Finally, the thickness of the slats of the drum could be reduced. None of these modifications would seem to significantly affect the operability or functionality of the thresher, and would lead to a major reduction of weight, size, and cost.

\section{Reliability}

The tedious and inconsistent insertion of the loops was resolved by the quick thinking of an experienced woodworker. This serves to highlight the importance of local expertise in the execution of a design, but it also indicates a flaw in the design of the loops themselves which should be remedied in a second iteration. To enhance the capacity of this machine to be built and maintained, the wire loops must be easier to install and less prone to damage during assembly. This could potentially be accomplished by devising another means or method of attaching the loops, by using stiffer wire for the loops, or both.

The decision to use bicycle parts, though expedient to the prototyping process, proved to be more difficult to implement than initially anticipated. Although the chain and sprocket design was eventually demonstrated as valid means of driving the drum via a treadle, lack of experience and tools for the support of bicycle disassembly and repair challenged the execution the treadle design and ultimately limited its usefulness. Ultimately, this result underscores the need for an appreciation of both cultural and technical realities in the field of design for the developing world. In the specific case of a treadle thresher for La Jalca, it is clear that reliable, desirable design would not include the use of bicycle parts.

\section{Usability}

The treadle was shown to be an intuitive mode of use for Jalquinos, and stands as is a successful demonstration of culturally-appropriate design. However, there is an issue with the treadle that significantly affected the overall usability of the machine. The treadle was not stiff enough to withstand depression under use. The springy action of the treadle made it difficult to keep a consistent rhythm during operation, making it difficult to maintain the speed of the drum. Compounding this issue, when quinoa was placed in the 
path of the drum, its rotational velocity slowed dramatically, and required the user to bring the drum back up to speed in order to continue the threshing process. To achieve and maintain the appropriate speed of the drum with minimal coordination, a stiffer treadle should be built.

\section{Value}

Because many of the materials and labor associated with the development of this initial prototype were donated, it is somewhat difficult to accurately assess the economic benefits of the use of this thresher by quinoa farmers. Furthermore, because the suggested modifications to the current design include finding a suitable replacement for the bicycle parts, the precise cost of a more suitable solution, and the underlying value it could provide to the quinoa farmer in La Jalca would necessarily be the subject of future work.

In this chapter, design alternatives for the construction of quinoa thresher were considered. These were synthesized into a single design with the input of local craftsmen in the community of La Jalca. During the construction and demonstration of the prototype, several opportunities were identified for improving the desirability of subsequent designs, with the most important being the substitution of standardized parts in place of bicycle parts where appropriate. Regardless of the flaws in the initial prototype, it was shown that it is possible to construct a functional quinoa thresher in La Jalca, resulting from close collaboration with local experts. This suggests a promising direction of future work in La Jalca to develop desirable products to the needs of the community that are currently unserved. 


\section{Chapter 5: Conclusions and Future Work}

This report describes the process of using human-centered design for the development, construction, and operation of a human-powered, open-drum quinoa thresher for use in rural Peru. First, it was observed that the international and domestic demand for quinoa has led to its increased production throughout Peru, to the economic benefit to producers at all scales of production. Noting the excessive losses associated with the traditional methods for processing quinoa, it was suggested that an improved means of threshing quinoa could result in greater economic benefit to small farmers in the poorest regions of Peru like the town of La Jalca in the Northern Peruvian Andes.

With a historical perspective on the evolving approaches to design for the developing world, it was proposed that an improved thresher would be more likely to be adopted if created for the specific context of La Jalca, which could be achieved through the application of human-centered design techniques. Elaborating upon HCD philosophy that products be "desirable" as a pretext for their adoption, a framework of six criteria of desirability was described, being the elements of Affinity, Usability, Functionality, Value, Reliability and Accessibility. This framework was then used to inform the design process of a desirable thresher in two ways: the first, to illuminate desirable and undesirable characteristics of existing threshers; the second, to identify opportunities for improving the desirability of a prototype thresher constructed in La Jalca.

From the assessment of existing threshing alternatives, both mechanized and semimechanized, it was determined that large, expensive motorized threshers would have limited utility within the geographic and economic reality of La Jalca, whereas portable, open-drum, treadle-driven threshers may possess a higher level of desirability in this context. Finally, the design and construction of such a thresher in La Jalca is described. A discussion of the functional initial prototype through the lens of desirability recommends, among other modifications, the pursuit of alternatives to bicycle parts for delivering power as the design approaches one more suited for wider production and distribution. 


\subsection{Conclusions}

In this study, human-centered design and a framework for describing product desirability were used to suggest a means of improving how quinoa farmers in La Jalca currently thresh their crop. Applying this methodology, it was determined that the current mechanization solutions in Peru would be unlikely to be adopted in the context of La Jalca, as they possess certain undesirable characteristics, including an inability to access the fields they are meant to serve. Observing the success of threshers in other contexts using this methodology presented a shortlist of features that might be desirable in a quinoa thresher, namely, affordability and portability. While further work to systematize the measurement of desirability is needed, its application in this manner offers a promising tool for incorporating user input in order to prioritize desirable design features and to understand why some alternatives are slow to be adopted.

The design and construction of a functioning prototype was undertaken in the field with the input of local welders, woodworkers, and members of the quinoa cooperative, whose help was invaluable. The successful demonstration of a treadle-powered thresher, one produced in La Jalca, is testament the potential of human-centered co-design for product development in a low-resource setting. That being said, the modifications suggested for improving on this prototype, which were described through the lens of desirability, may have been avoided with a methodical treatment of the HCD. Moreover, it is possible that, given its apparent usefulness in post-facto analysis, the desirability criteria might be better integrated into the prototyping phase from the onset.

To the specific point of the difficulties encountered in the development of the prototype, bicycles were used because of their immediate availability, these should not be pursued in designs moving forward, as they compromise the desirability of a final design. In a cultural context where bicycles are a novelty, there is no support system for their continued use. Even so, the local expertise of welders and carpenters enabled the construction of the frame and drum, in spite of these difficulties, which suggests that improvements to the design could be reliably maintained locally. 


\subsection{Future work}

The most immediate, impactful continuation of this study would be the refining and testing of the treadle thresher in La Jalca or a similar quinoa-growing region. This should be done systematically, employing the framework of desirability to measure positive change between designs. The first of these iterations should improve upon the functionality of the initial prototype. In addition to the replacement of bicycle parts, one important modification of would be a redesign of the treadle mechanism, which would improve usability. Additionally, the rotational speed of the drum should be optimized and fixed. While these technical issues are being corrected, quantitative data regarding the threshing efficiency, grain removal efficiency, and grain removal speed should be measured relative to traditional techniques, to assess an acceptable level of functionality. Simultaneously, fieldwork should be performed with the intent of improving the desirability of the thresher with respect to factors other than functionality. This would include a more rigorous survey of Peruvian users to understand aesthetic and emotional value associated with the thresher, a demonstration of its portability, and a complete estimate of its cost and labor saved. With these data, aimed at achieving a threshold level of desirability, an organization or individual could consider the implementation of this thresher beyond the design stage.

Avoiding design pitfalls and increasing adoption rate of a product depend on improved methodologies for understanding and integrating user voice throughout the design stage. In this way while the physical result of this work is a functional quinoa thresher prototype, it is to be hoped that this demonstration of human-centered design and the application of a desirability framework improve the process of product development for users in the developing world, resulting in better outcomes for designer and user alike. 


\section{Bibliography}

G. Aroni et al., "Traditional processes and technological innovation in quinoa harvesting, processing, and industrialization," State of the Art Report of Quinoa in the World in 2013. FAO and CIRAD. Rome, Italy, 2015.

D. Bazile, et al., State of the Art Report on Quinoa around the World in 2013, p. xiii, FAO and CIRAD. Rome, Italy, 2015.

M. Bellemare, et al., "Foods and Fads: The Welfare Impacts of Rising Quinoa Prices in Peru." March 2016.

L. Castillo et al., "Design Considerations for the Base of the Pyramid (BoP) Projects," Proceedings from the Cumulus Helsinki 2012 Conference. Helsinki, Finland, 2011.

P. Dunn, Appropriate Technology, p. 3-6. London, UK, 1979.

J. Gilliam et al., "Failure Modes for Agricultural Technology Ventures in Developing Countries." At National Collegiate Inventors and Innovators Alliance Conference, 2011.

H.J. Hopfen, Farm Implements for Arid and Tropical Regions, Food and Agriculture Organization of the United Nations, Rome, Italy. 1969.

IDEO, Human-Centered Design Toolkit, 2009.

INEI, PERÚ: Estimaciones y Proyecciones de Población por Sexo, según Departamento, Provincia y Distrito, 2000-2015, pp. 95. INEI. Lima, Peru, Dec. 2009.

INEI, Perú: Perfíl de la Pobrbreza por Dominios Geográficos 2004-2015, pp. 231266. INEl. Lima, Peru, 2016. [Online]. Available:

https://www.inei.gob.pe/media/MenuRecursivo/publicaciones_digitales/Est/Lib1370/l ibro.pdf

ITDG Agricultural Equipment and Tools No. 37: Foot Powered Thresher, Intermediate Technology Publications, London, United Kingdom. 1985.

W. Kacheba, "Consumer judgement of the quality of informal sector products: Lessons for innovative microentrepreneurs," Technovation, vol. 17, no. 2, pp. 91105, 1997.

MINAGRI, Sistema Integrado de Estadística Agragria, pp. 10-13. MINAGRI. Lima, Peru, 2015. 
Fundación para la Promoción e Investigación de Productos Andinos - PROINPA. Prototipos: Trilladoras de Granos (Quinua, Cañahua, Amaranto). Technical Report, 1-3. 2008.

S. Salas Dominguez, "Quinoa - Postharvest and Commercialization," Food Review International, vol. 19, pp. 191-201, 2003.

Selco Foundation, "Testing of small scale threshing machines in rural Karnataka," Technical Report. Selco Foundation, 2013.

J. G. da Silva, et al., Passos para a Construção de Três Trilhadoras de Arroz, EMBRAPA, 2011.

K. P. Singh, et al., "Optimisation of machine parameters of pedal-operated paddy thresher using RSM," Biosystem Engineering, vol. 100, 2008.

X. Slaski and M Thurber, "Cookstoves and Obstacles to Technology Adoption by the Poor," Working paper \#89. Freeman Spogli Institute for International Studies. 2009.

S. Subrahmanyan, Integrated approach to understanding consumer behavior at bottom of pyramid," Journal of Consumer Marketing, vol 25, no. 7, 2008.

T. Whitehead, Enhancing New Product Development in Low Income Economies. (PhD Thesis). Loughborough Design School. Loughborough University, United Kingdom, 2015. 